\title{
Cundill Centre Online Tool for the Treatment of Youth Depression
}

\section{LAUNCH}

November 9, 2021

Dr. Peter Szatmari, Dr. Stephanie Ameis, Renira Narrandes

Cundill Centre for Child and Youth Depression, CAMH, Toronto

Panel: Melanie Asselin, Dr. Karin Euler 


\section{Outline}

1. Introduction

2. The project in a poem

3. Live demo

4. Youth engagement in this project

5. Panel 


\section{Child and Youth Depression; a Public Health Challenge}

- A common disorder of children and youth; roughly $10 \%$ of the population

- Many barriers to care

- Response to treatment is around 40\%

- Many drop out of treatment before treatment completed

- Roughly 50\% go on to another, more severe, episode

- Long term impact on education, occupation, and adult mental health

- No new significant advances in treatments in over 40 years 
The Cundill Centre for Child and Youth Depression at the Centre for Addiction and Mental Health (CAMH), Toronto, Canada

The Cundill Centre for Child and Youth Depression focuses on developing best practices for the screening, prevention and treatment of child and youth depression. We aspire to have a global impact on research, care and knowledge exchange in this field.

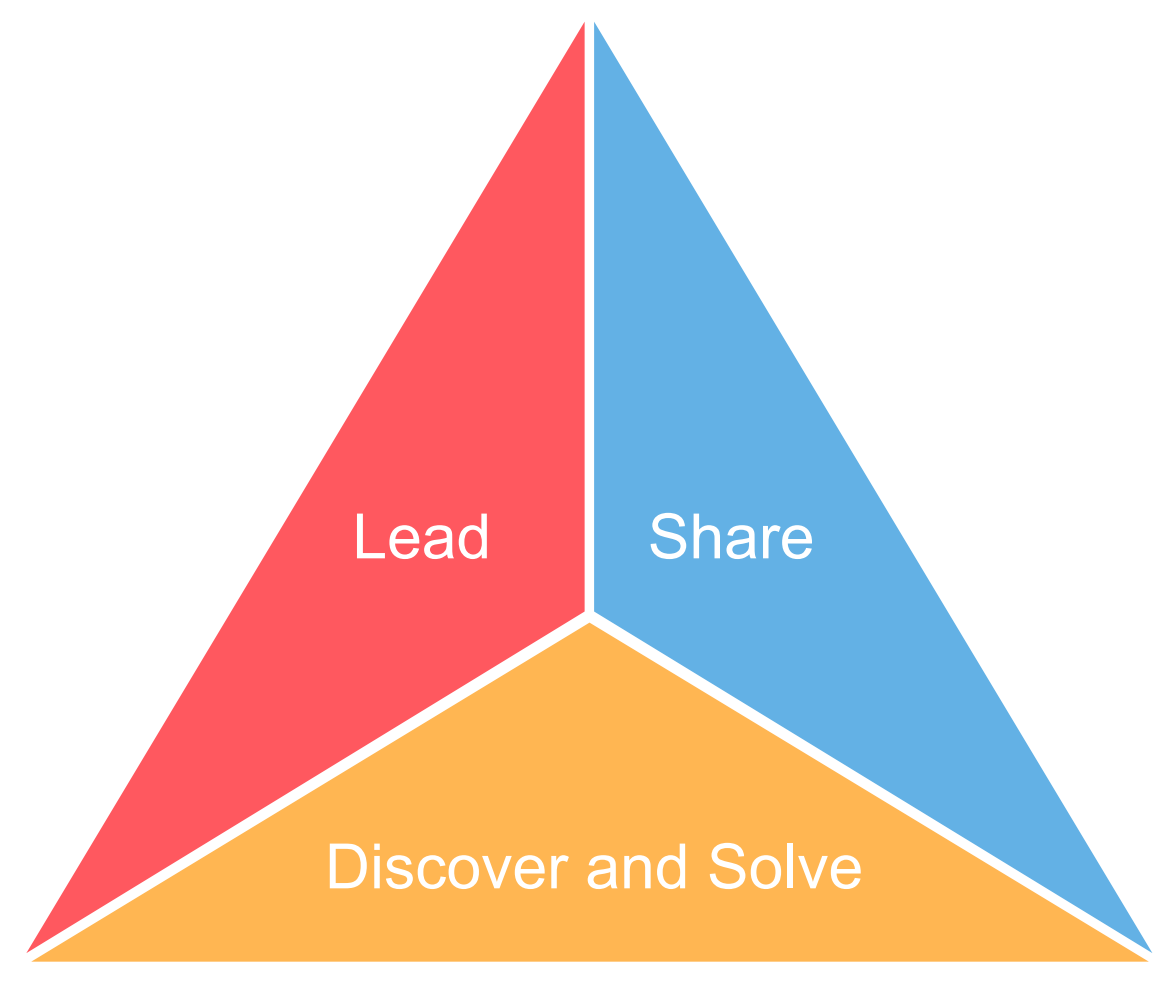




\section{Knowledge Translation (KT)}

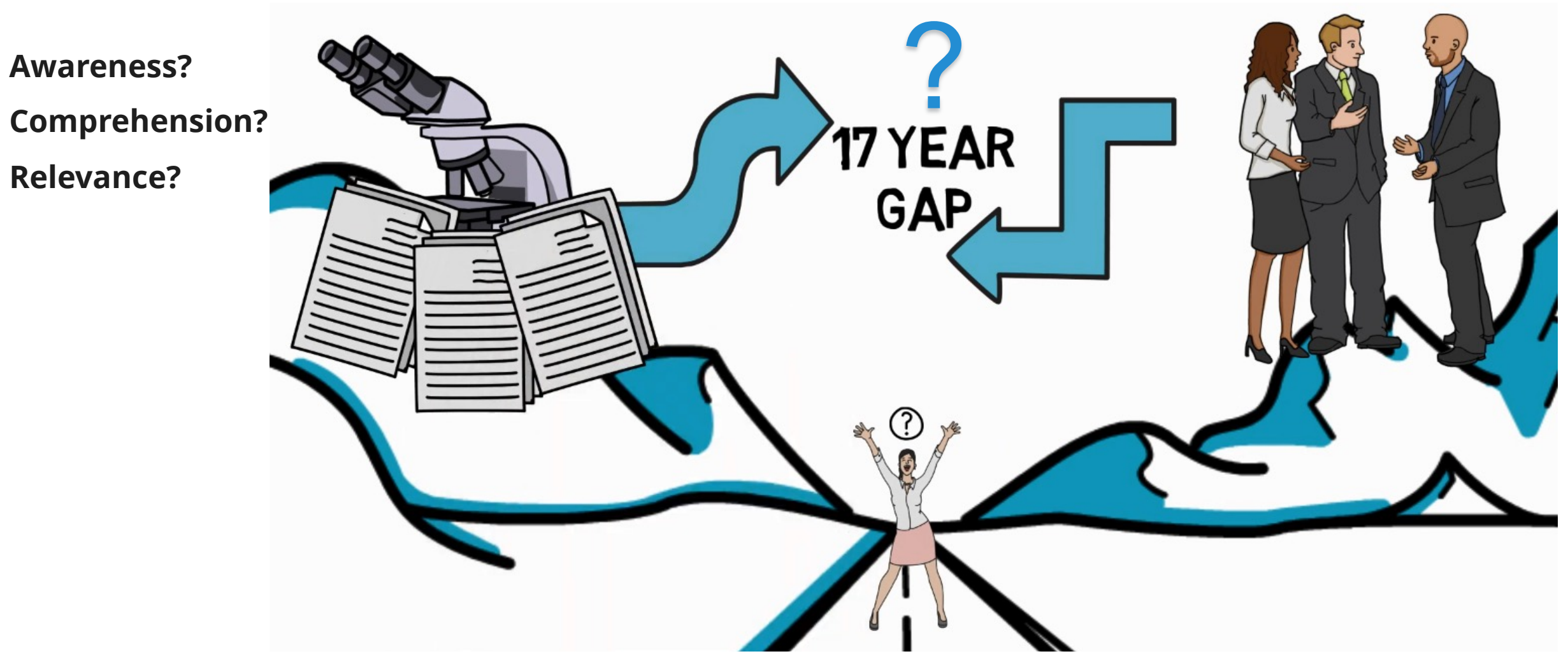

"... a dynamic and iterative process that includes synthesis, dissemination, exchange and ethically-sound application of knowledge to improve the health of Canadians, provide more effective health services and products and strengthen the health care system."

$-\mathrm{CIHR}, 2016$ 


\section{Online Tool Contributors}

\author{
Cundill Centre for Child and Youth Depression, CAMH \\ Renira Narrandes, Knowledge Translation Specialist \\ Dr. Stephanie Ameis, Lead Clinical Advisor \\ Dr. Peter Szatmari, Clinical Advisor \\ Dr. Darren Courtney, Clinical Advisor \\ Dr. Madison Aitken, Clinical Advisor \\ Dr. Priya Watson, Clinical Advisor
}

\section{Provincial System Support Program, CAMH}

Mahfuz Hassan, BCBA, Instructional Designer

Dr. Natalia Ronda, Manager, Instructional Design and Learning Technologies

Dr. Branka Agic, Director, Knowledge Exchange

\section{Design}

Chase, Shuyang Liu, Web Developer/Designer

Youth Engagement Initiative, supported by the Margaret and Wallace McCain

Centre for Child, Youth \& Family Mental Health and the Child, Youth and

Emerging Adult Program at $\mathrm{CAMH}$.

Melanie Asselin

Zara Uddin

Em Hayes

Karleigh Darnay 


\section{A Spoken Word Poem}

\section{Online Tool for Treating Youth Depression}




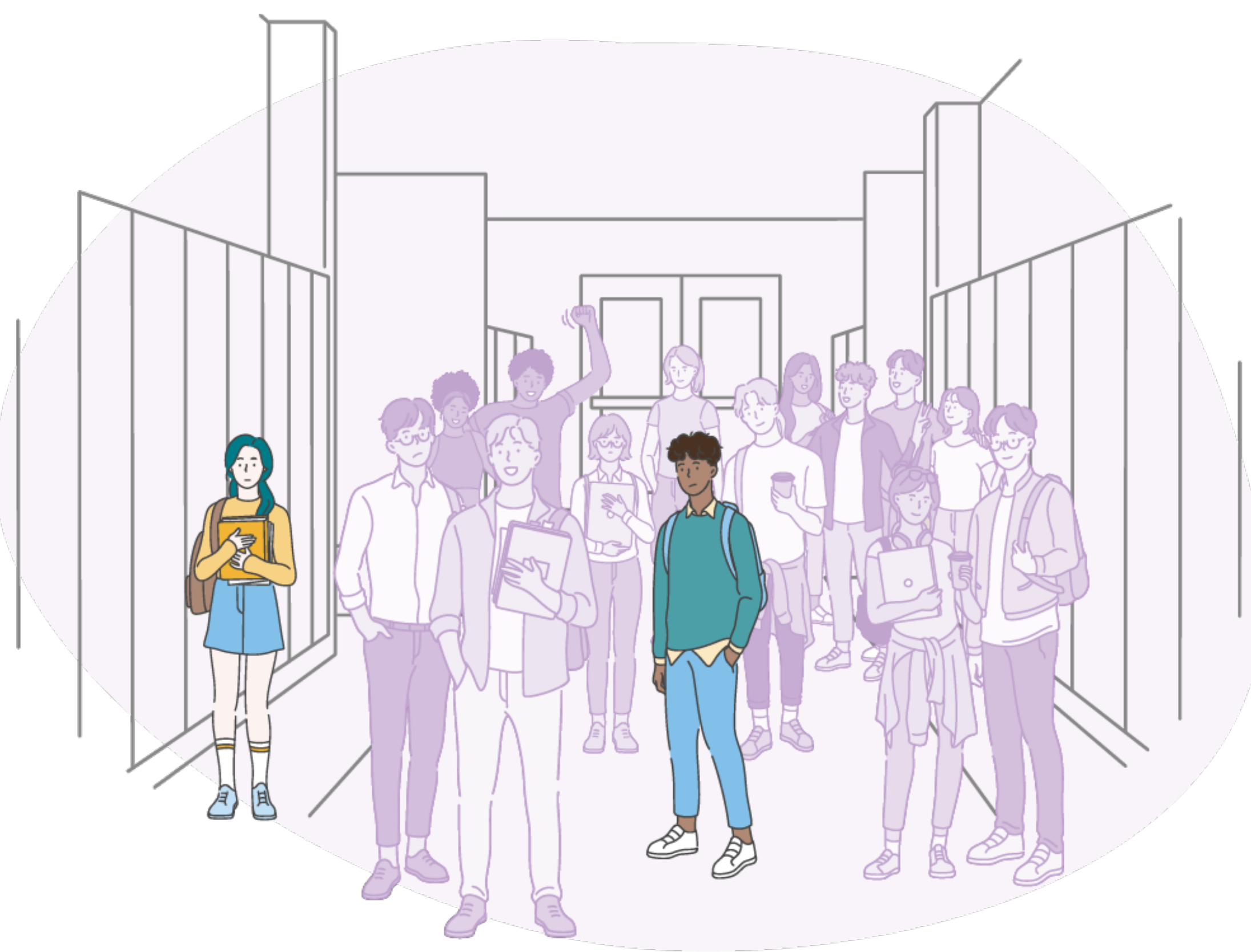


Long wait times

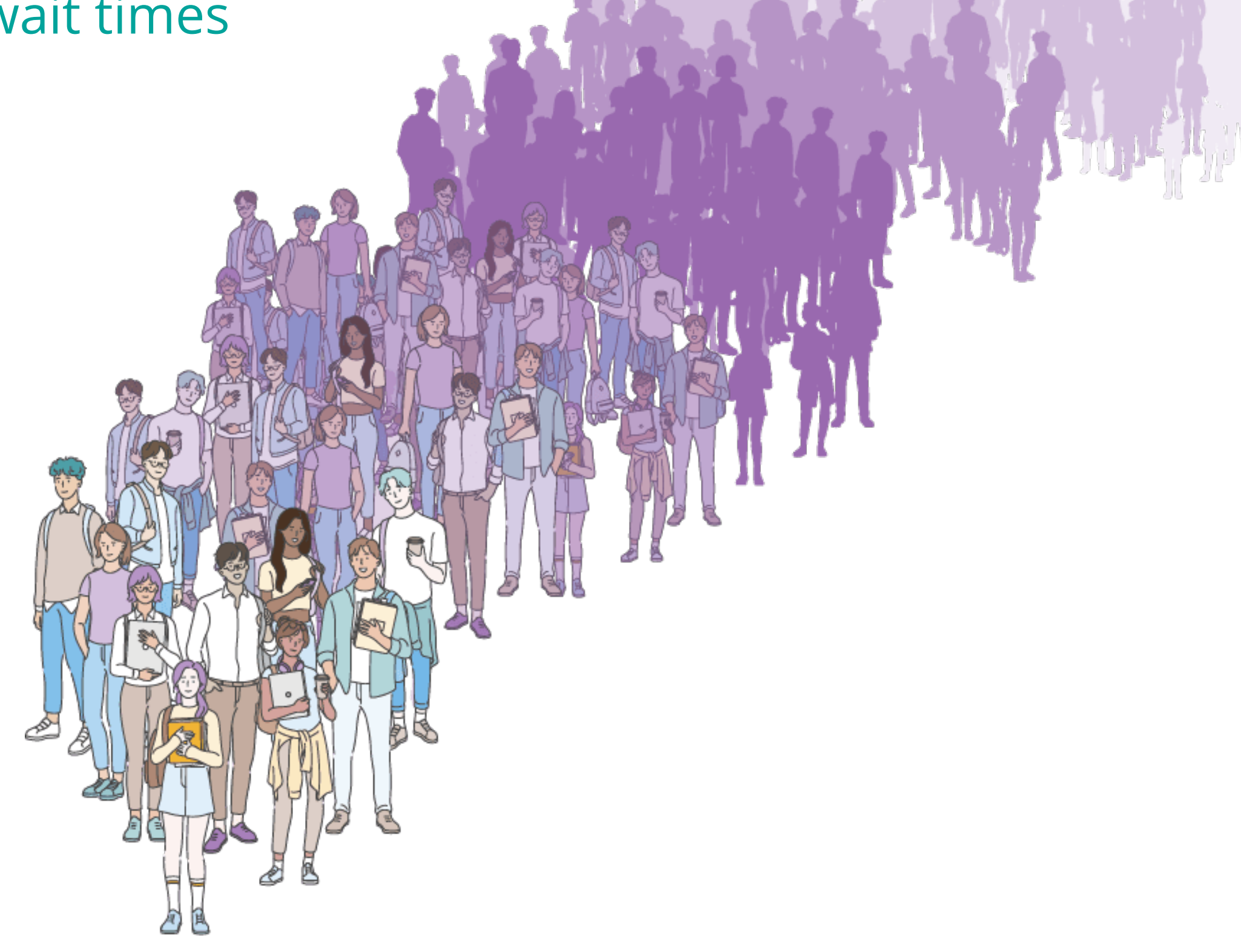



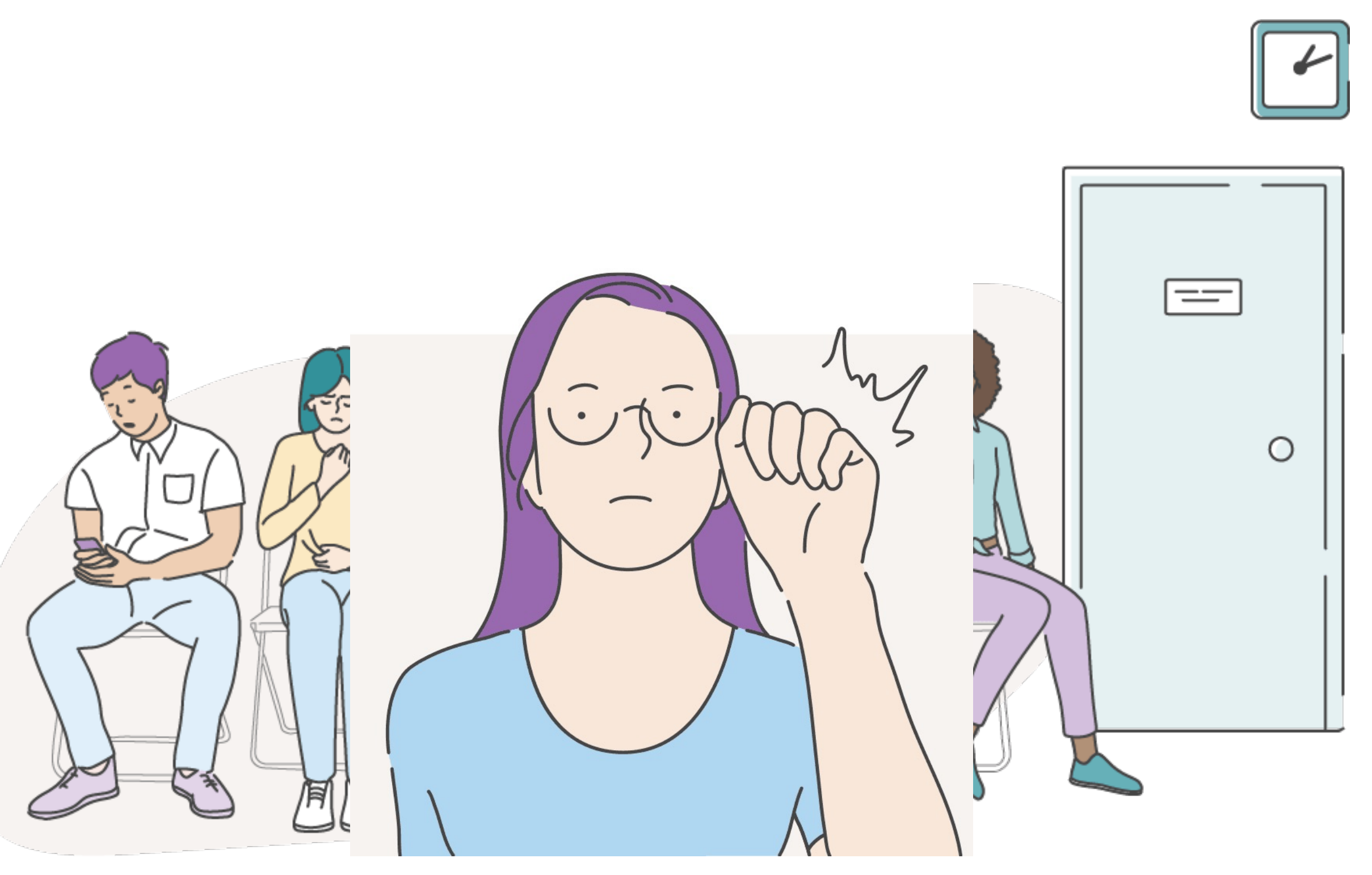
Refer to higher levels of care

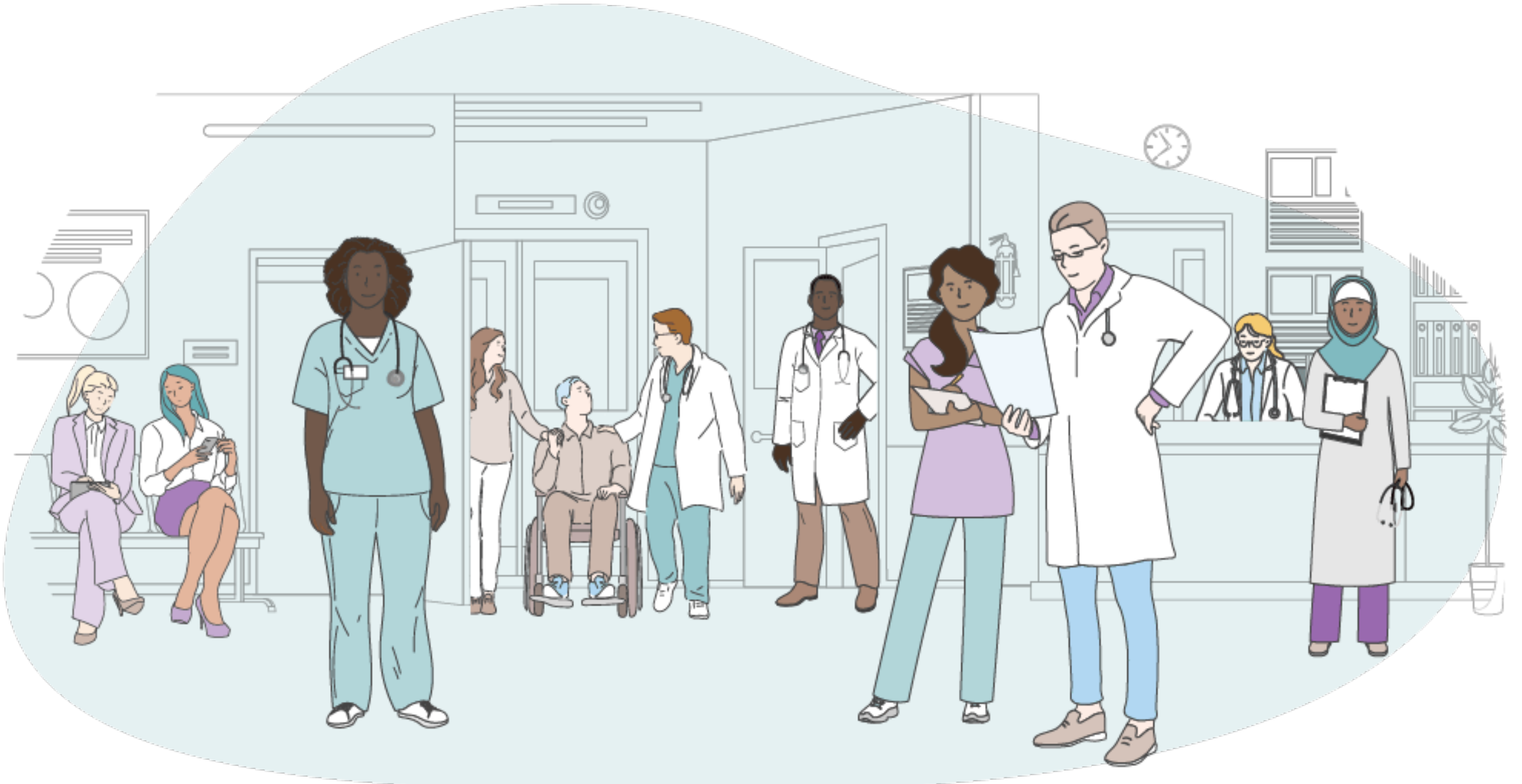




\section{Ontario: Services for kids differ by location}

Watson et al. BMC Health Services Research
https//doiorg/10.1186/s2 (2019) 19:947

RESEARCH ARTICLE

Service provision for depressed children and youth: a survey of the scope and nature of services in Ontario

Priya Watson "๑, Kamna Mehra, Lisa D. Hawke and Joanna Henderson
BMC Health Services Research

Q

Check tor
updates

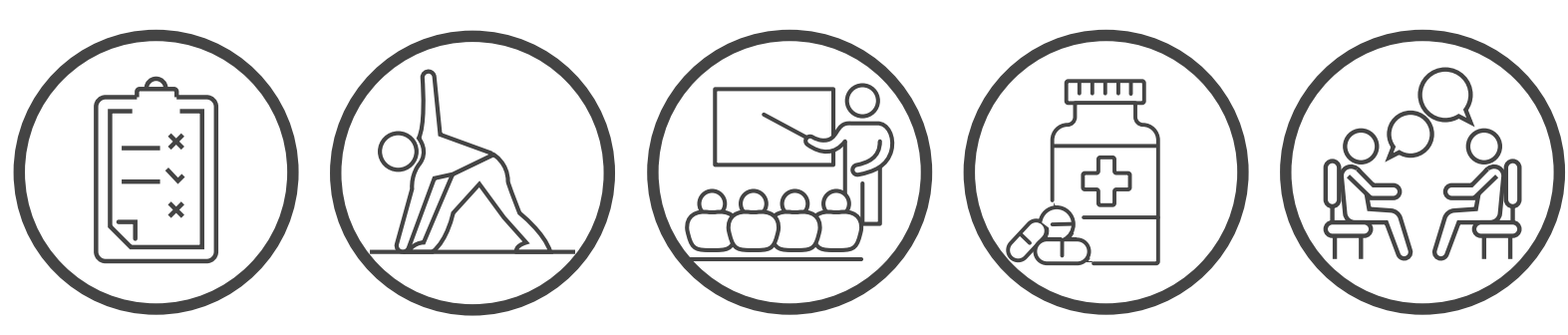


Find evidence-based practices to treat and assess 


\section{Build primary care capacity to do their best}


Online tool for primary care providers from east to west

Outline evidence-based practices for youth depression

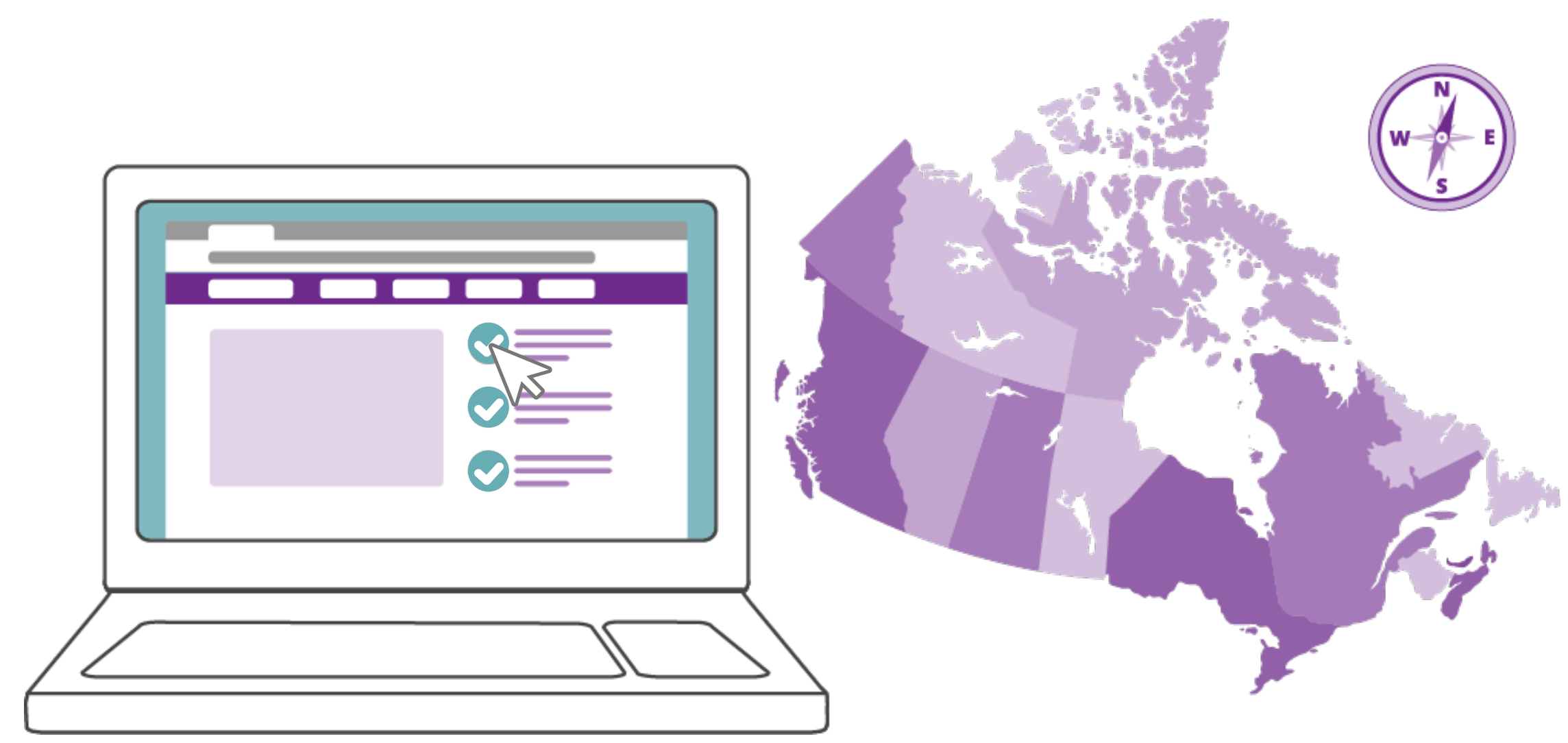




\section{STEP ONE: Systemic review}

Review > Depress Anxiety. 2018 Jun;35(6):530-540. doi: 10.1002/da.22752. Epub 2018 Apr 26.

An appraisal of the trustworthiness of practice guidelines for depression and anxiety in children and youth

Kathryn Bennett ${ }^{1}$, Darren Courtney ${ }^{2}{ }^{3}$, Stephanie Duda ${ }^{1}$, Joanna Henderson ${ }^{3} 4$ Peter Szatmari 25

Affiliations + expand

PMID: 29697887 DOI: 10.1002/da.22752

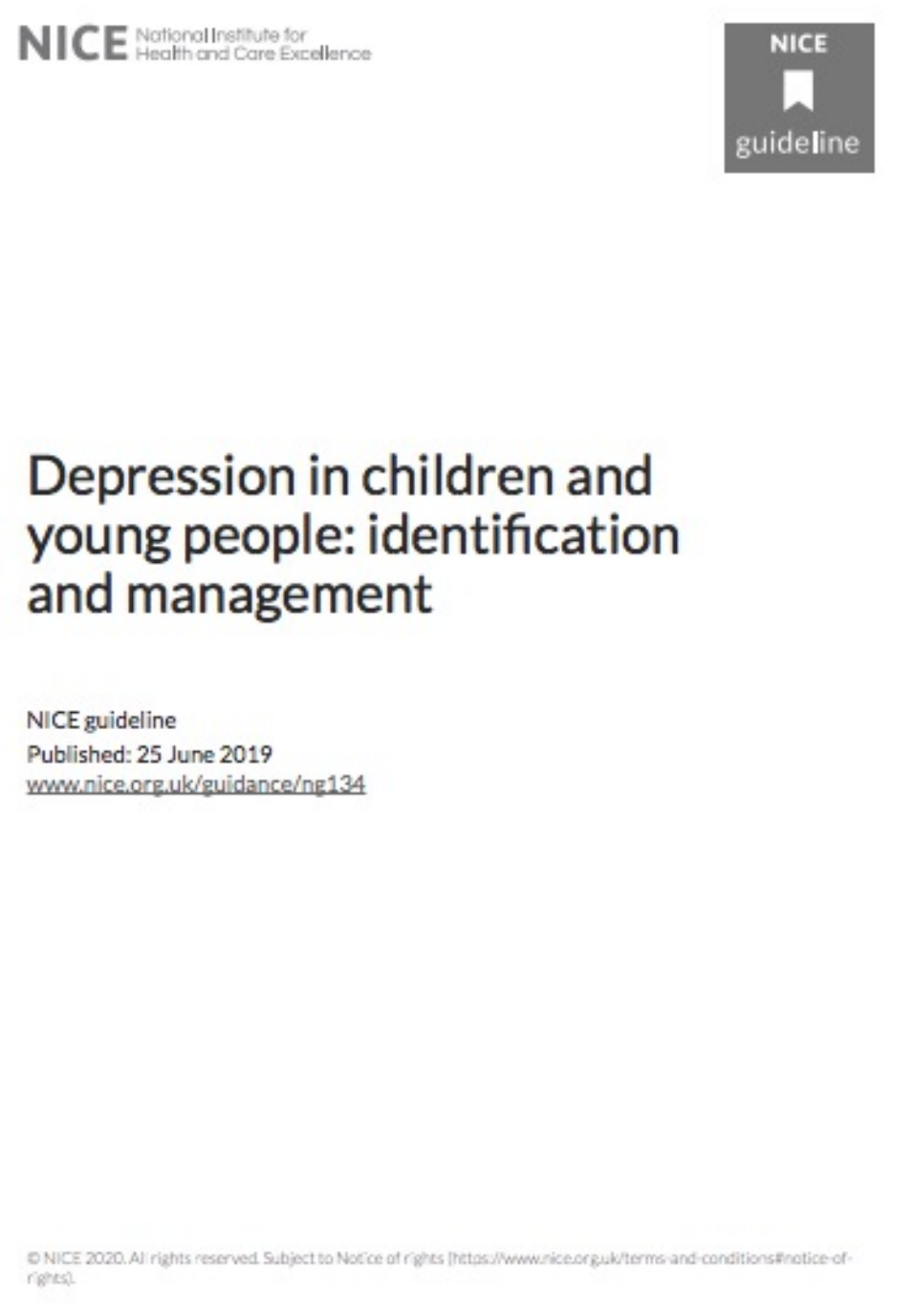


STEP TWO: Develop a decision aid

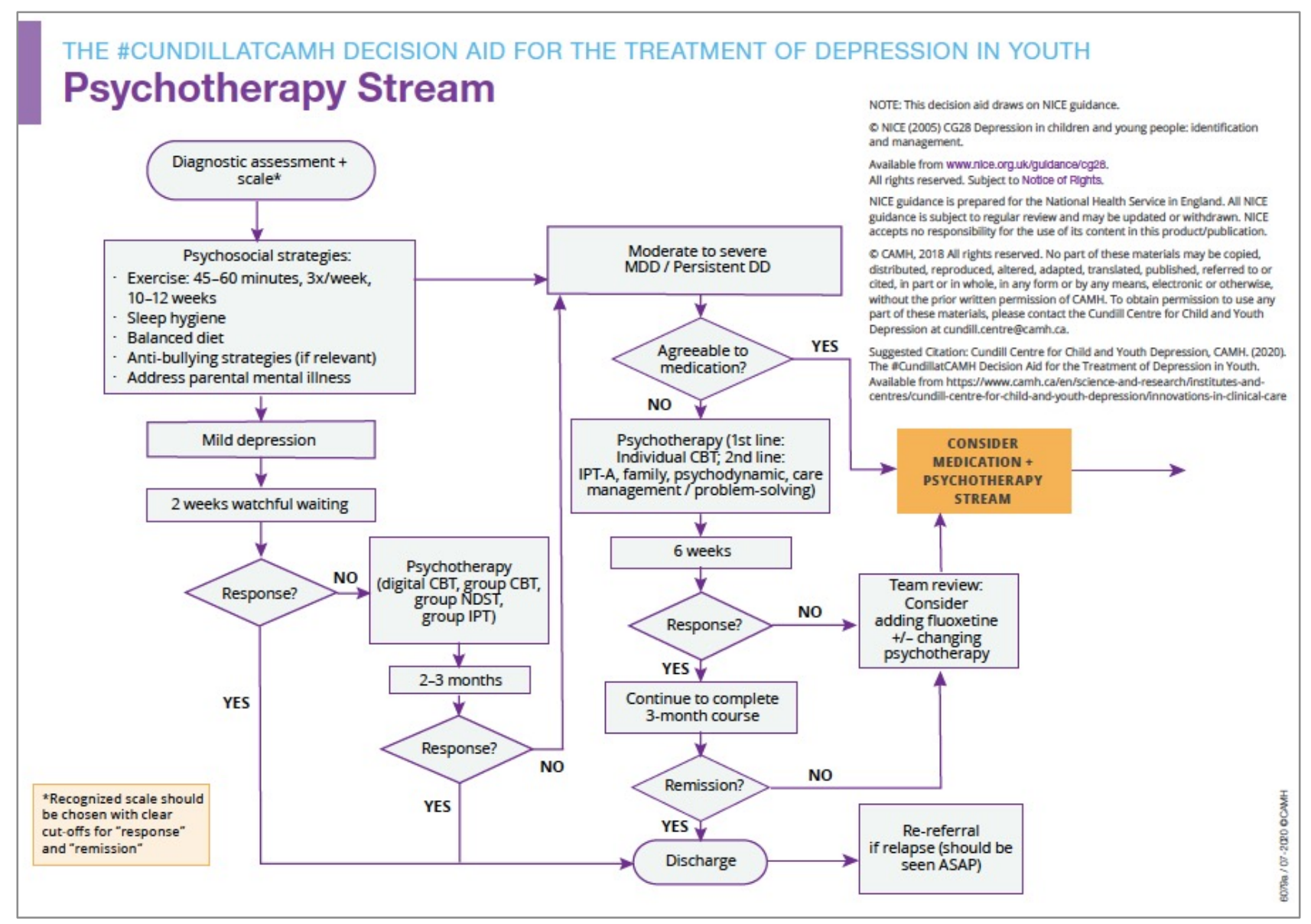




\section{STEP THREE: Make the tool}

\author{
Cundill Centre for Child and Youth Depression, CAMH \\ Renira Narrandes, Knowledge Translation Specialist \\ Dr. Stephanie Ameis, Lead Clinical Advisor \\ Dr. Peter Szatmari, Clinical Advisor \\ Dr. Darren Courtney, Clinical Advisor \\ Dr. Madison Aitken, Clinical Advisor \\ Dr. Priya Watson, Clinical Advisor
}

\section{Provincial System Support Program, CAMH}

Mahfuz Hassan, BCBA, Instructional Designer

Dr. Natalia Ronda, Manager, Instructional Design and Learning Technologies

Dr. Branka Agic, Director, Knowledge Exchange

\section{Design}

Chase, Shuyang Liu, Web Developer/Designer

Youth Engagement Initiative, supported by the Margaret and Wallace McCain Centre for Child, Youth \& Family Mental Health and the Child, Youth and Emerging Adult Program at $\mathrm{CAMH}$.

Melanie Asselin

Zara Uddin

Em Hayes

Karleigh Darnay 


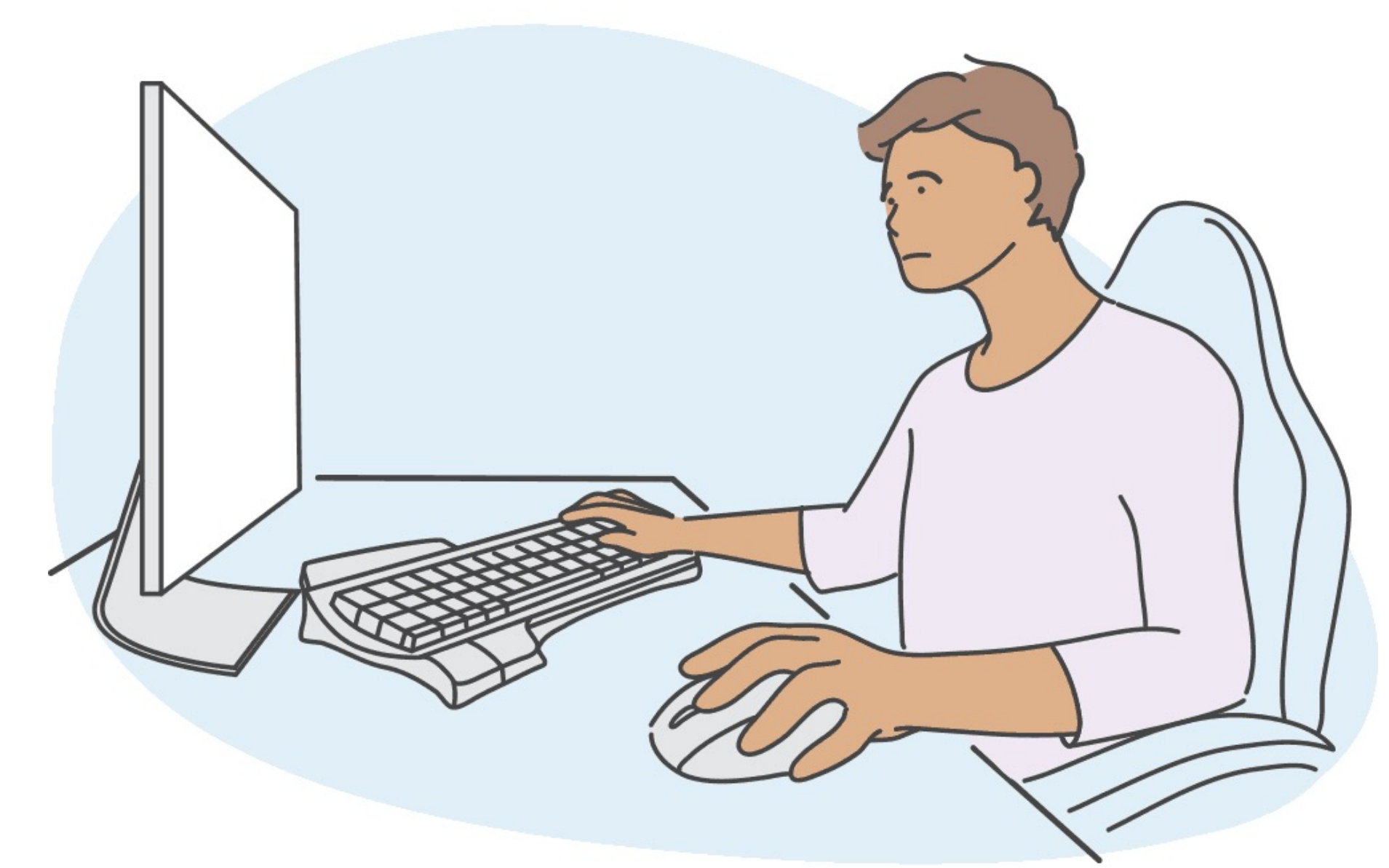


STEP THREE: Make the tool

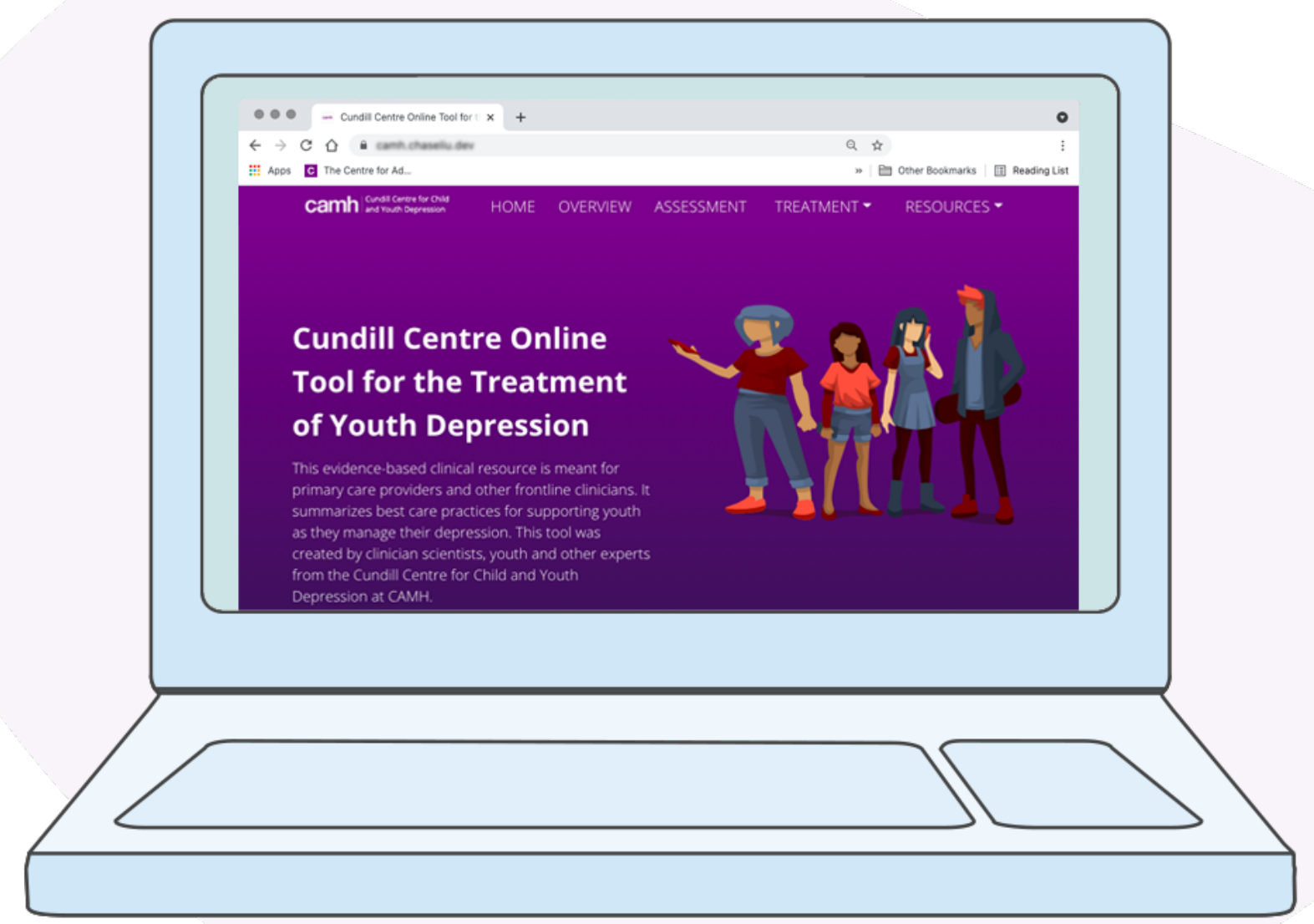




\section{Overview}

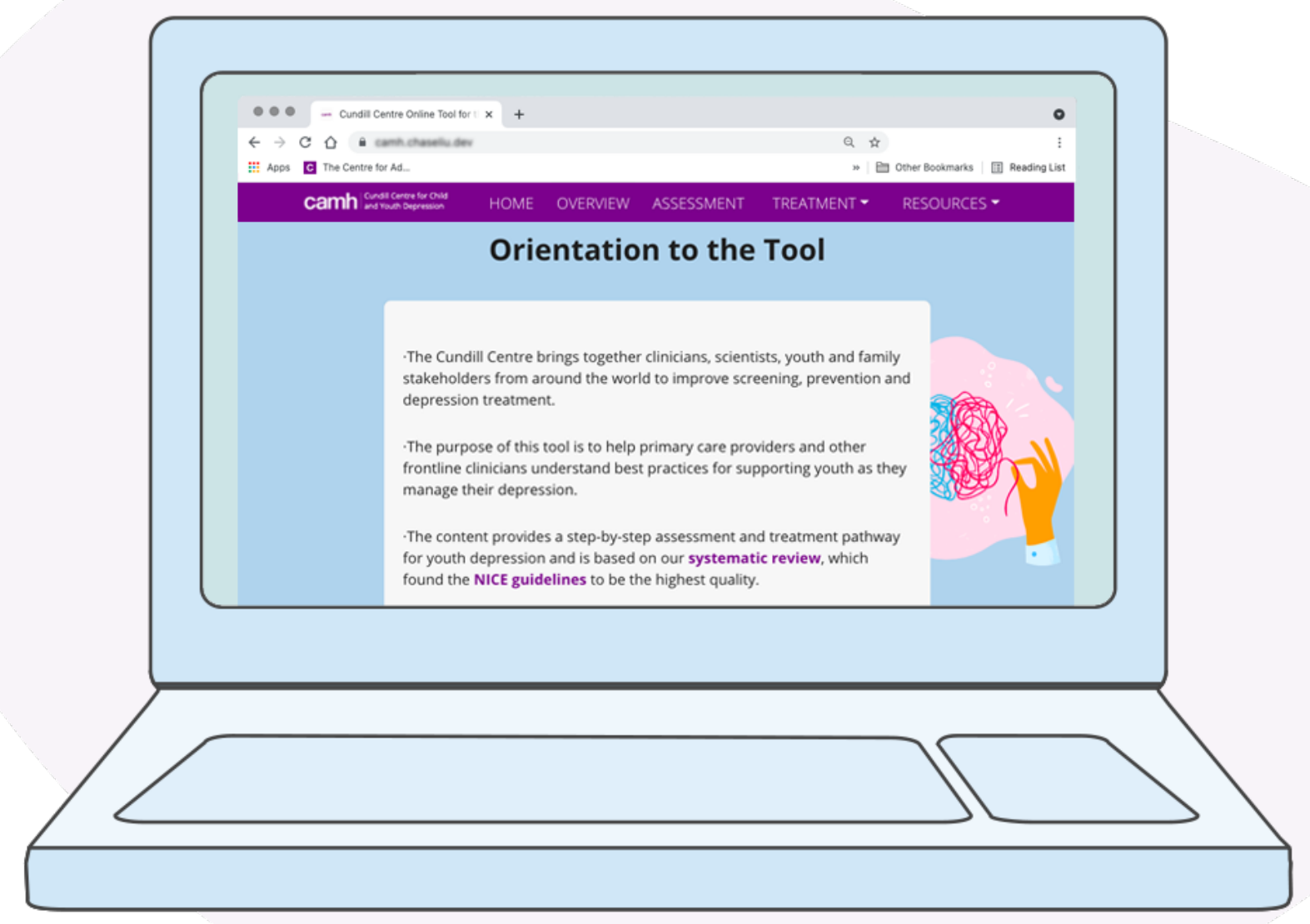




\section{Assessment}

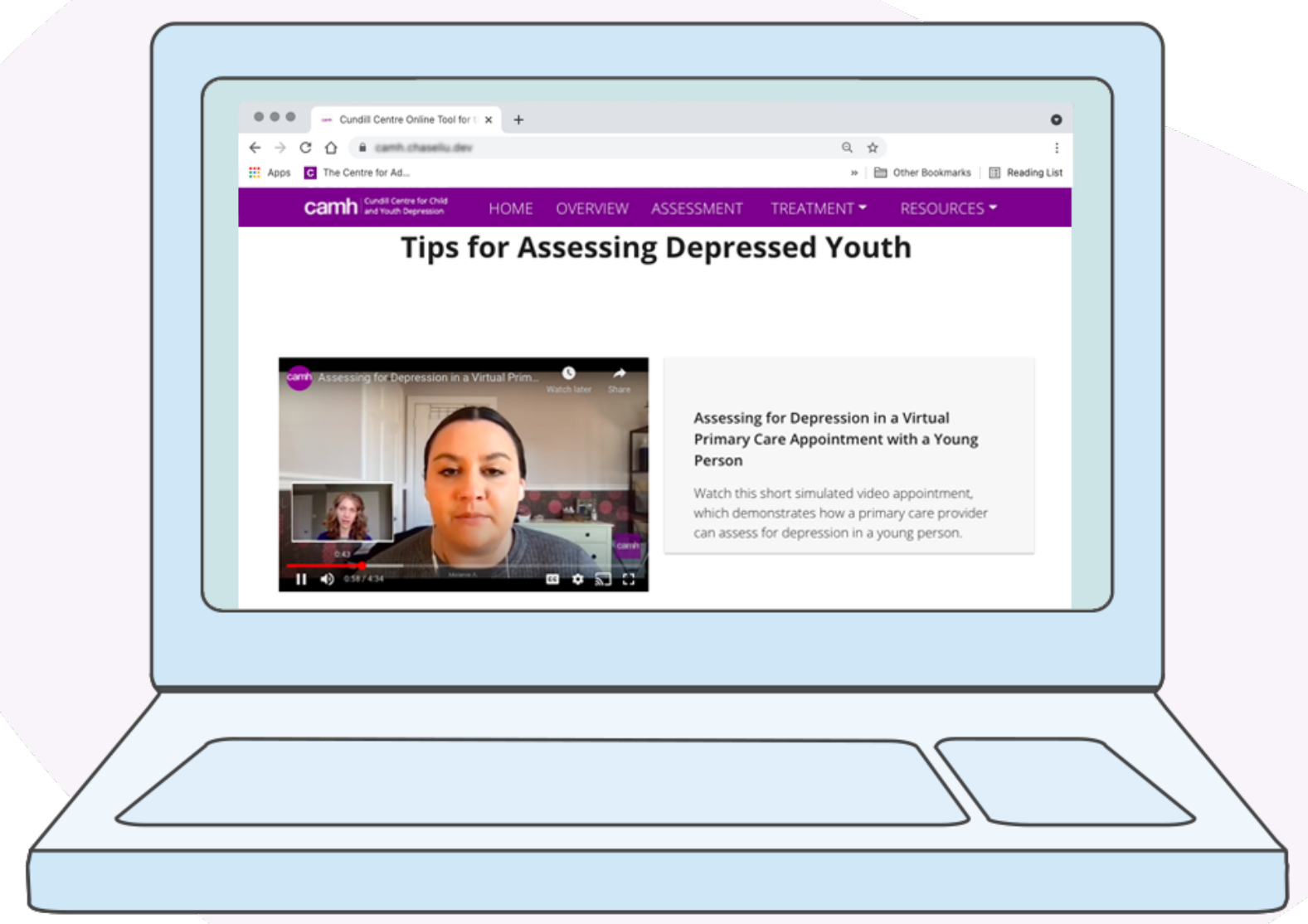




\section{Treatment}

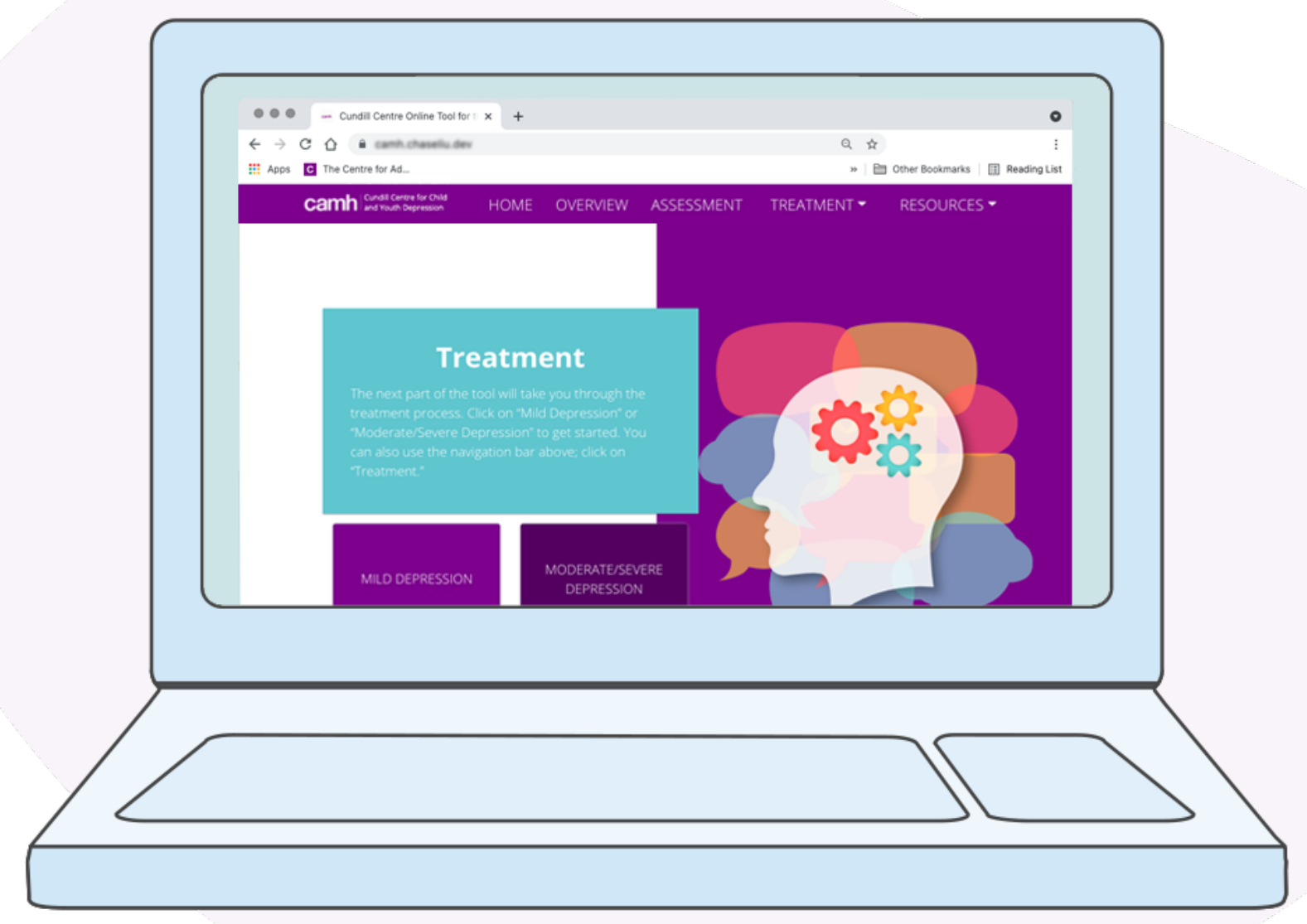




\section{Treatment}

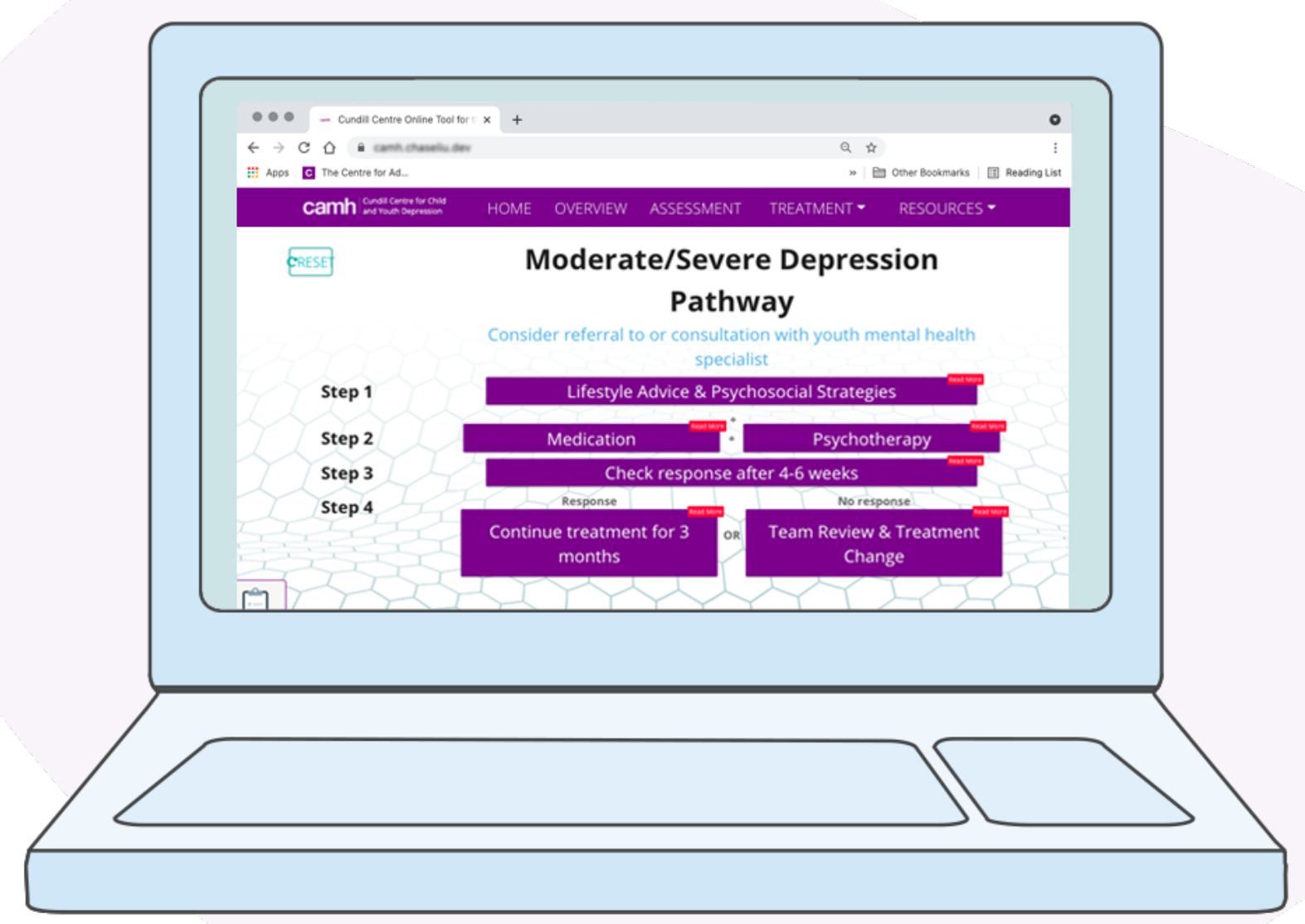




\section{Resources}

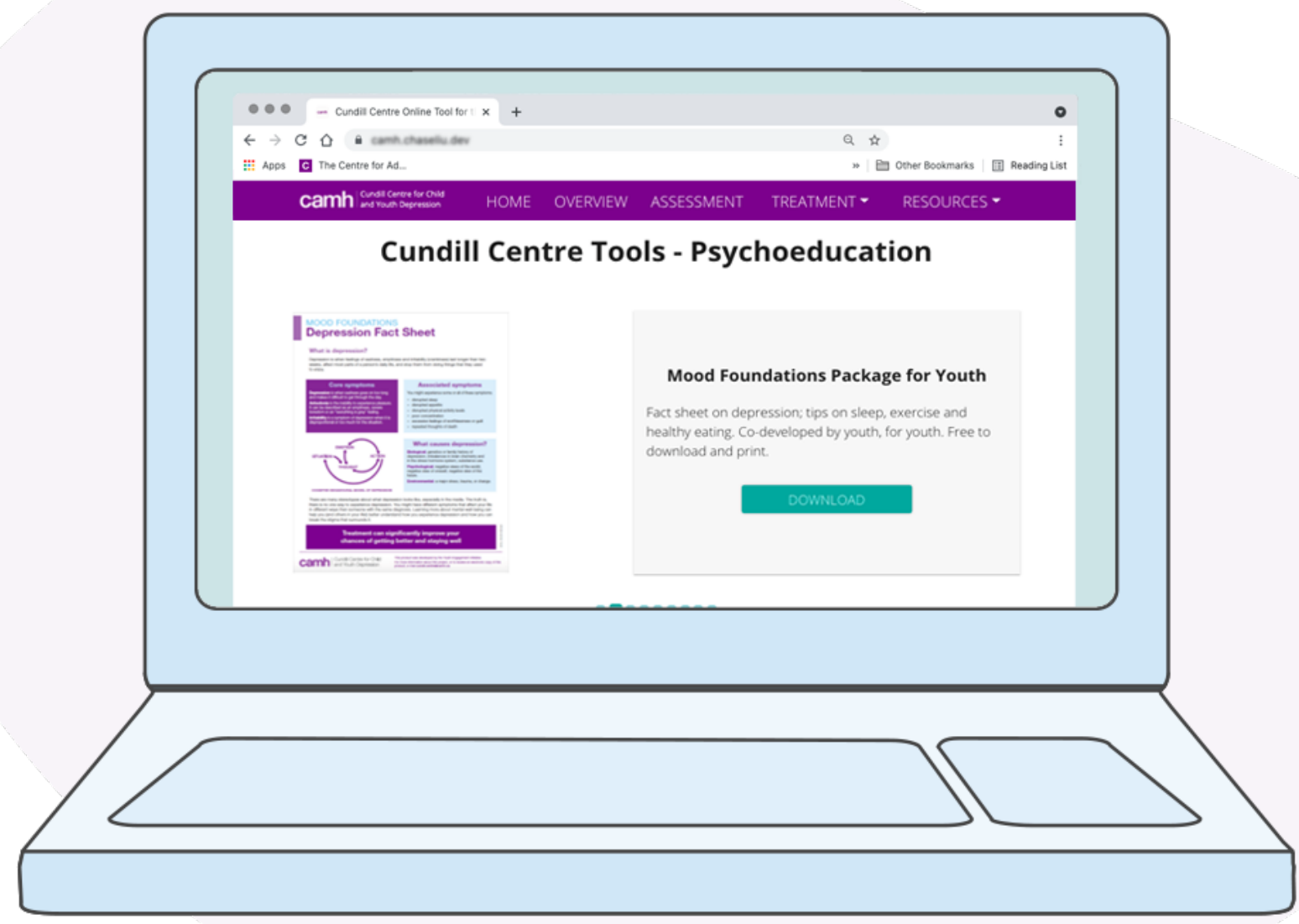




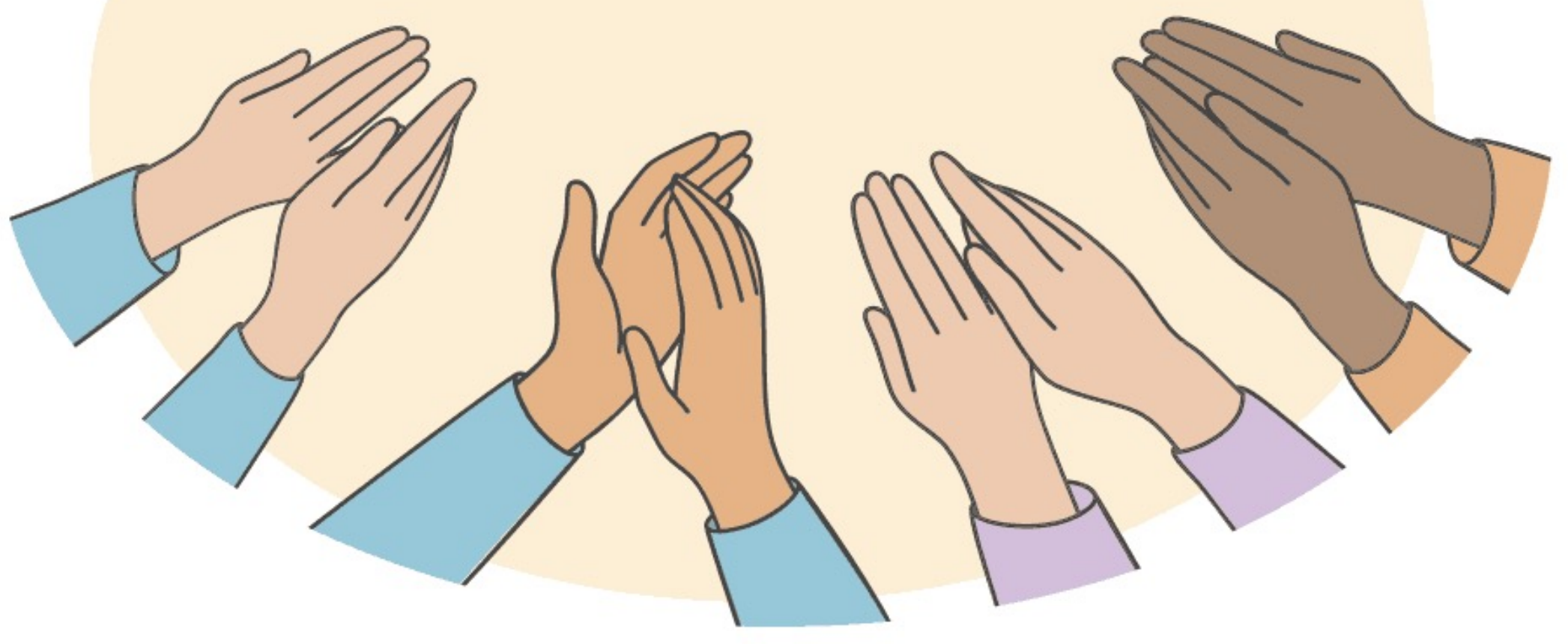




\title{
cundilldepressioncaretool.camh.ca
}

\author{
Cundill.Centre@camh.ca
}



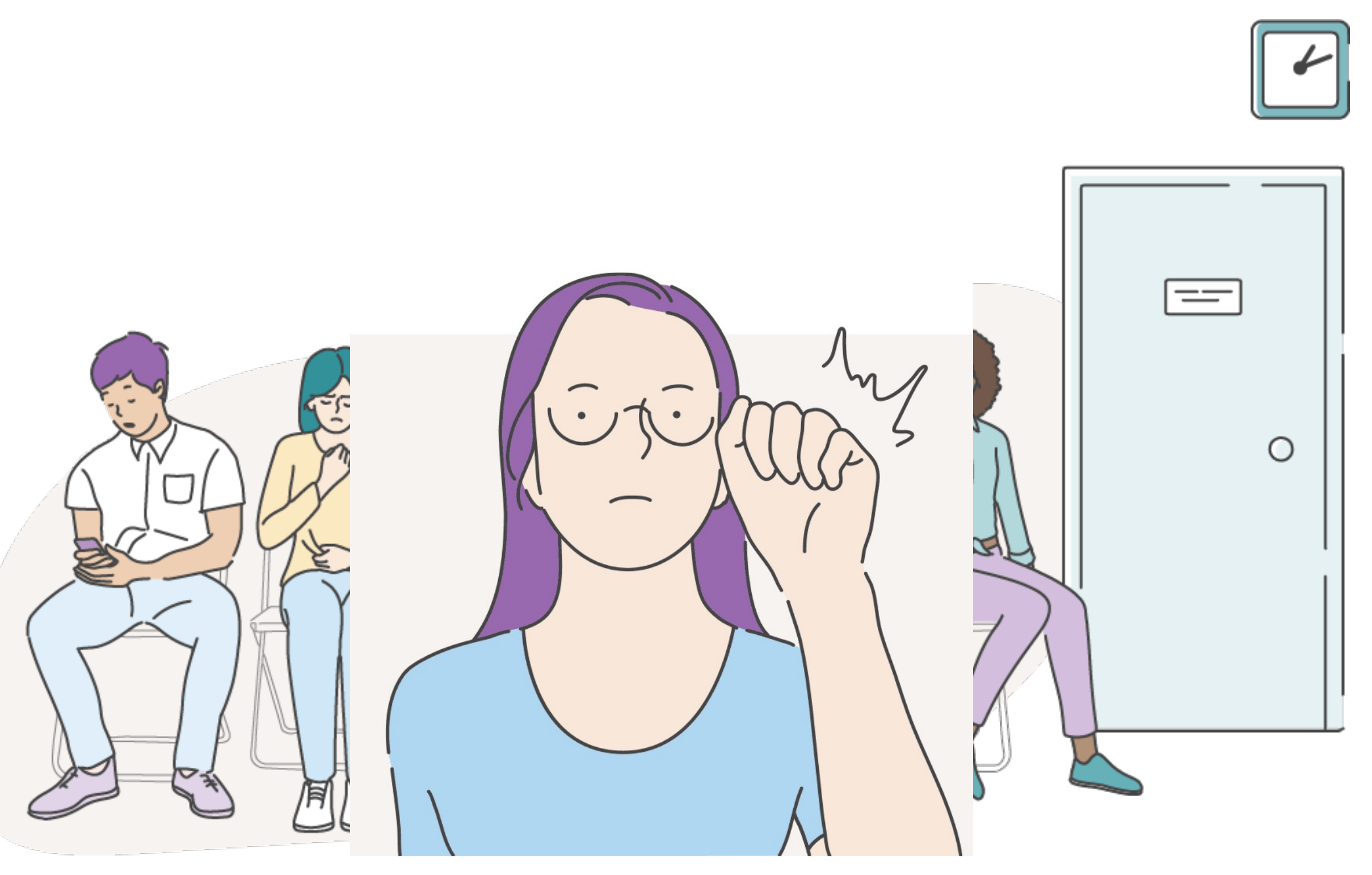


\section{Live Demo}

camh 


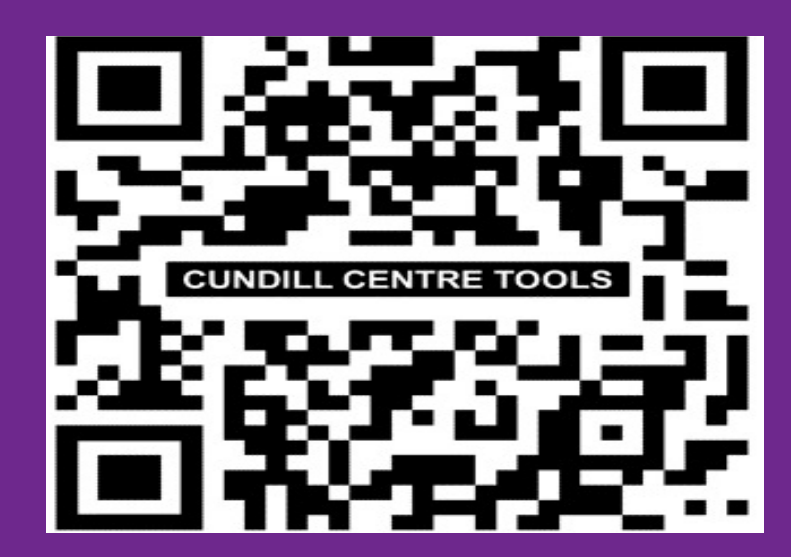

Direct link to online tool:

$\rightarrow$ cundilldepressioncaretool.camh.ca

Link to all Cundill Centre tools:

$\rightarrow$ cundillcentre.ca > Innovations in Clinical Care

Ask questions, leave comments, sign up to hear about the latest tools \& events:

$\rightarrow$ Cundill.Centre@camh.ca 
Youth Engagement in this Project 


\section{Why engage young people?}

- Youth voices are imperative to inform decision making and programming that directly impact youth.

- Collaborating with youth results in project and program goals, activities and outcomes that are more relevant and better reflect the needs of youth. 


\section{What we did}

- Team of 3 young people + a Youth Engagement Coordinator

- Reviewed the whole tool

- Provided feedback on using youth-friendly terms throughout the tool

- Planned and co-facilitated a Youth Advisory Group meeting with 15 other young people to discuss tips for conducting a good assessment 


\section{The original assessment video}

\section{camh ${ }_{\text {andill Cente for child }}^{\text {Cund }}$}

\section{Tips for Assessing Depressed Youth}

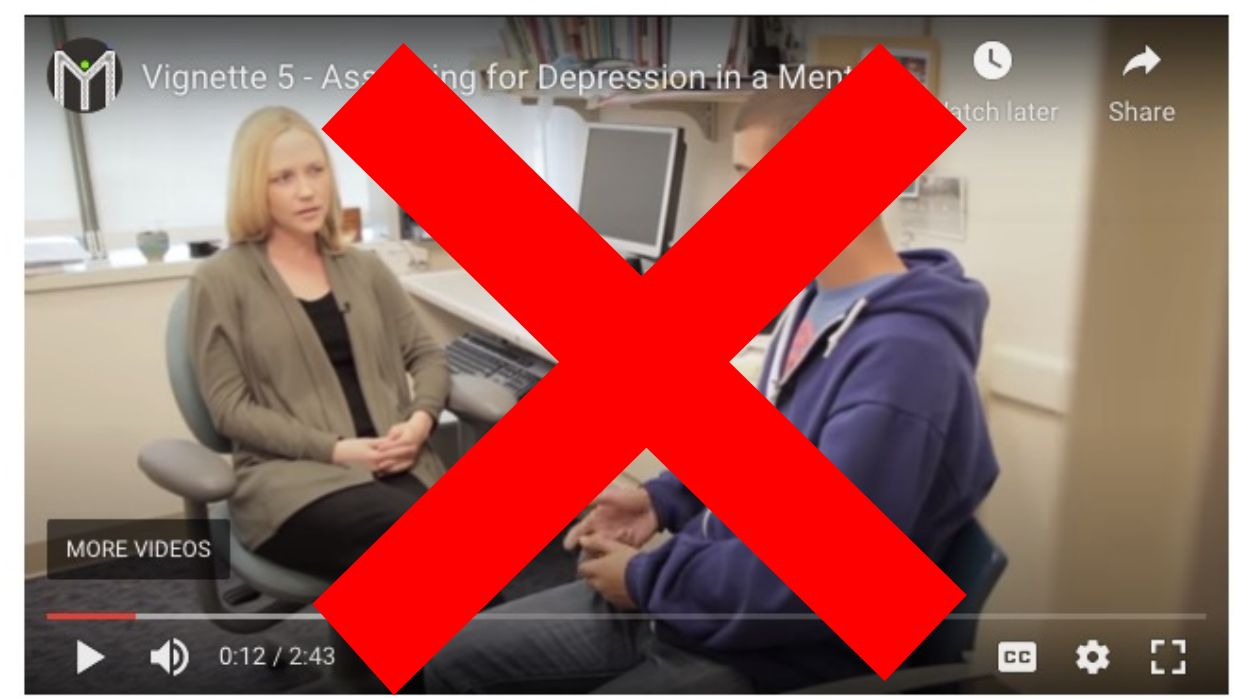

This short video features Tony, a youth who was referred to a social worker by his medical provider, due to concerns about depression and anxiety.

While you watch, think about what was helpful, and perhaps unhelpful, about the assessment approach. We will review afterwards. 


\section{The new assessment video}

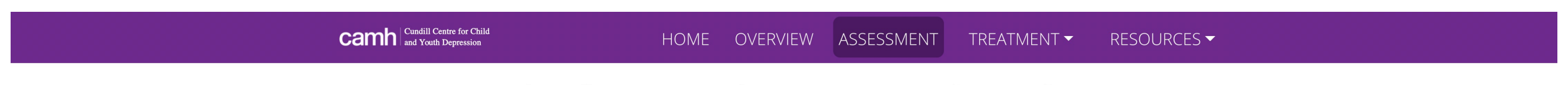

Tips for Assessing Depressed Youth

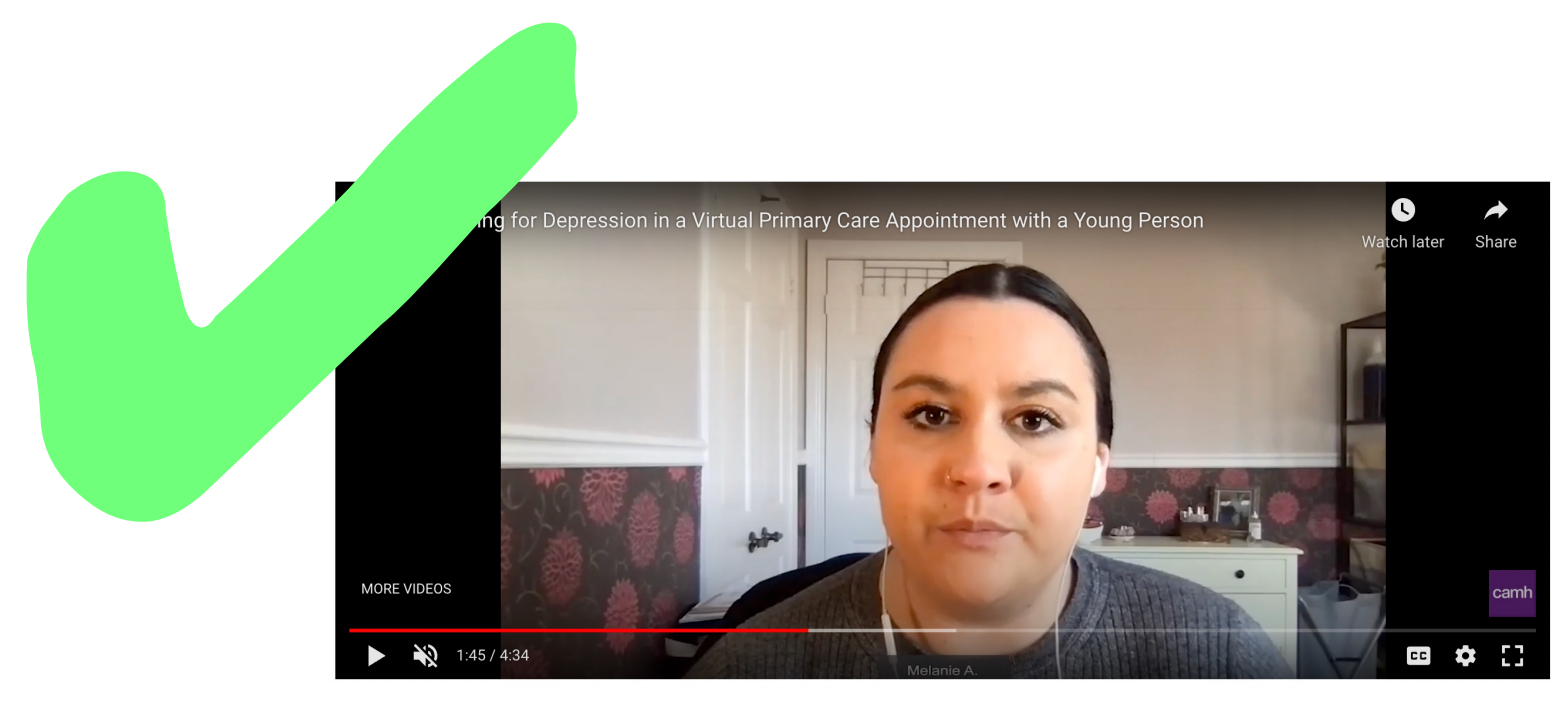

Assessing for Depression in a Virtual Primary Care Appointment with a Young Person

Watch this short simulated video appointment, which demonstrates how a primary care provider can assess for depression in a young person.
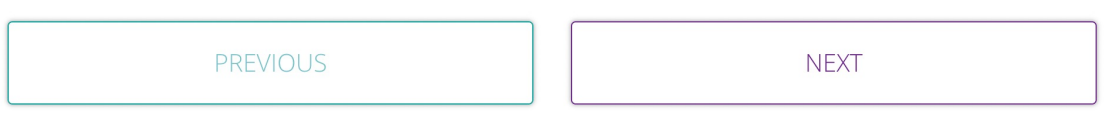

Copyright @ 2020 Cundill Centre for Child and Youth Depression camh. Development Team 


\section{Panel}

camh 


\section{Cundill Centre Tools: Integrated Care Pathways}

\section{Available for free in 3 ways:}

$\rightarrow$ cundillcentre.ca $>$ Innovations in Clinical Care

$\rightarrow$ or e-mail Cundill.Centre@camh.ca

$\rightarrow$ or SCAN the QR code

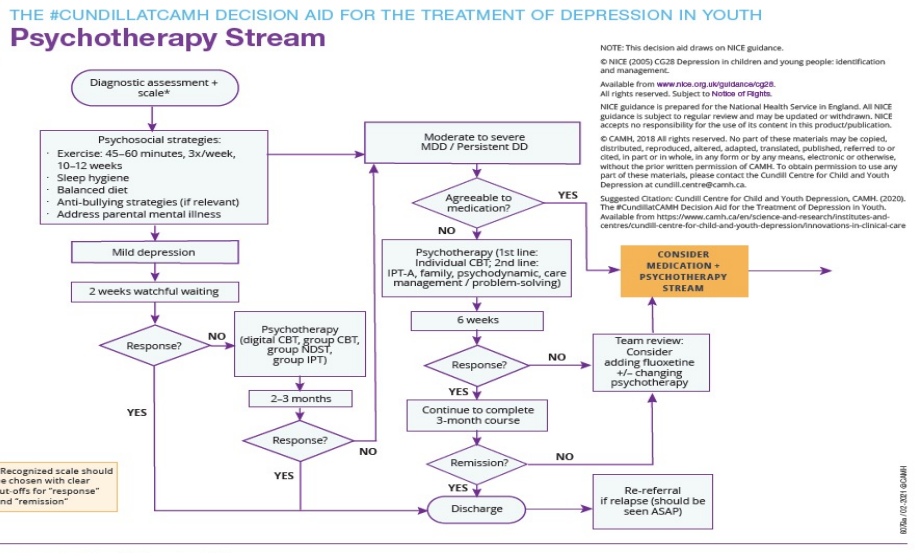

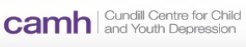

The \#CundillatCAMH Decision Aid for the Treatment of Depression in Youth

This 2-page flowchart helps guide health care providers in making treatment decisions for

youth who have depression. Based on

evidence-based clinical practice guidelines.
CARIBOU Integrated Care Pathway

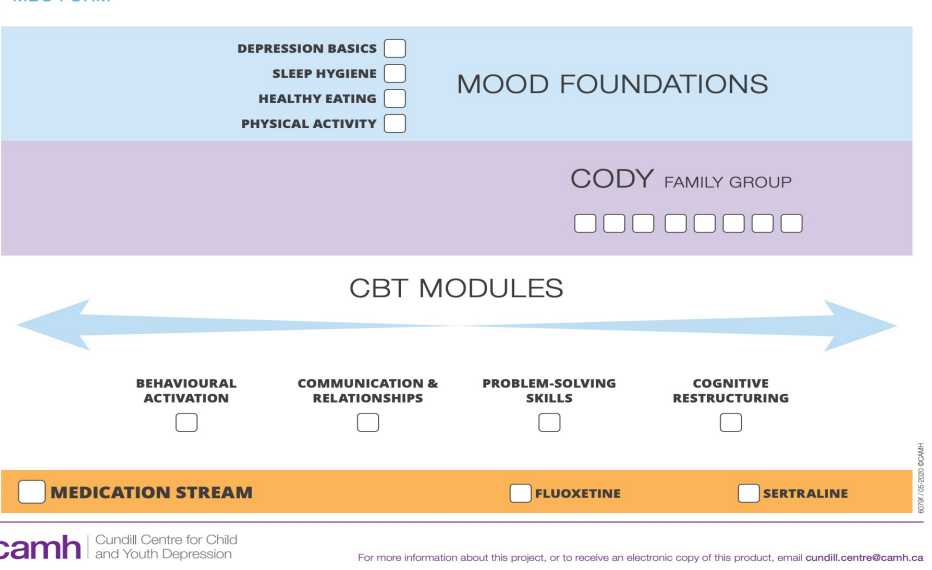

CARIBOU Integrated Care Pathway Manual This manual outlines the seven steps of the evidence-based CARIBOU Integrated Care Pathway for Adolescents with Depression. Includes materials required to implement the pathway.

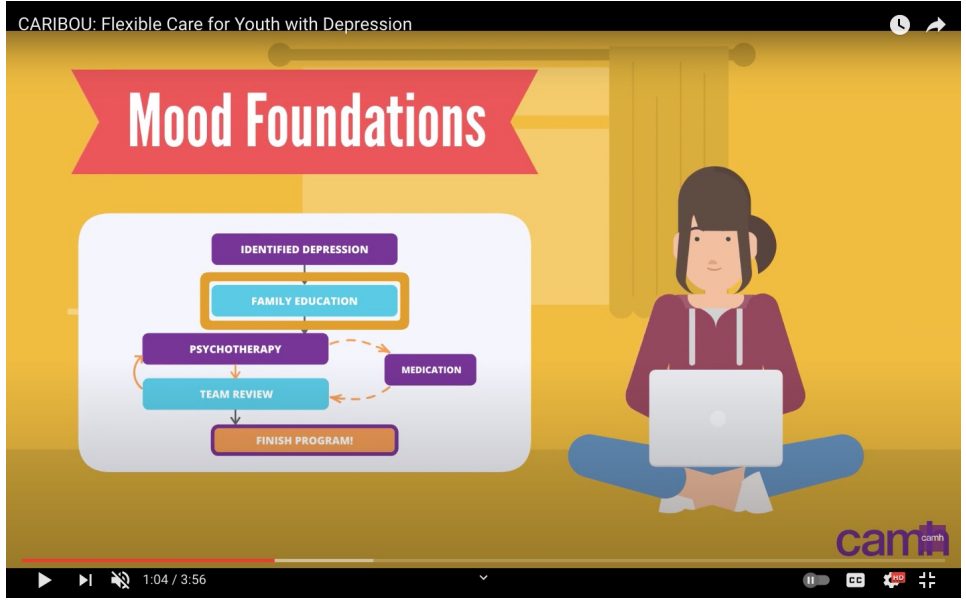

CARIBOU: Flexible Care for Youth with Depression

This video (3:56) was developed for youth, by youth to explain the CARIBOU Integrated Care Pathway for Adolescents with Depression. 


\section{Cundill Centre Tools:}

Screening, Assessment \& Measurement

\section{Available for free in 3 ways:}

$\rightarrow$ cundillcentre.ca $>$ Innovations in Clinical Care

$\rightarrow$ or e-mail Cundill.Centre@camh.ca

$\rightarrow$ or SCAN the QR code

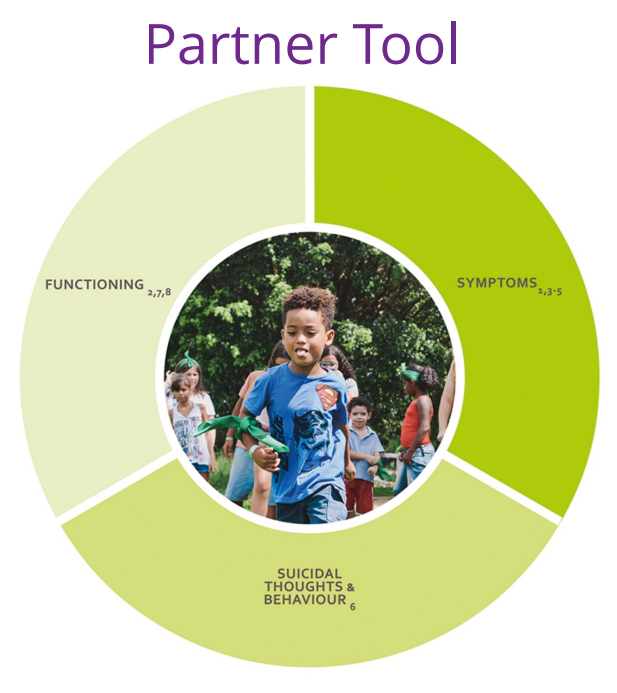

ICHOM Standard Set for Children and Young People with Depression \& Anxiety The International Consortium for Health Outcomes Measurement (ICHOM) has developed a standard set of outcome measures that matter most to children and young people with depression and anxiety. ICHOM is made up of leading global experts, including members of the Cundill Centre.

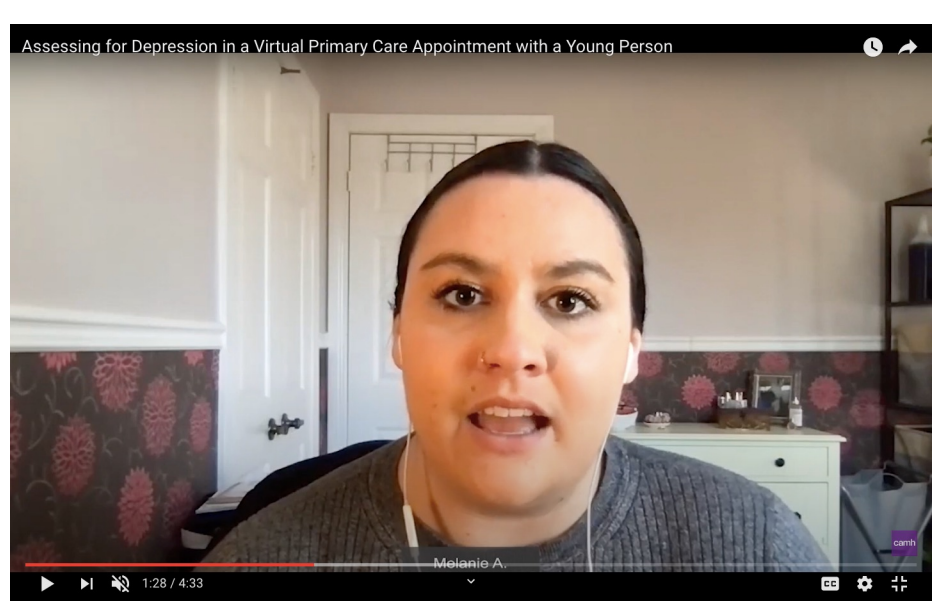

Assessing for Depression in a Virtual Primary Care Appointment with a Young Person

Meant for primary care providers, this simulation video (4:33) demonstrates how to assess for depression in a young person and highlights important questions to ask, including ones about self-harm.
Partner Tool

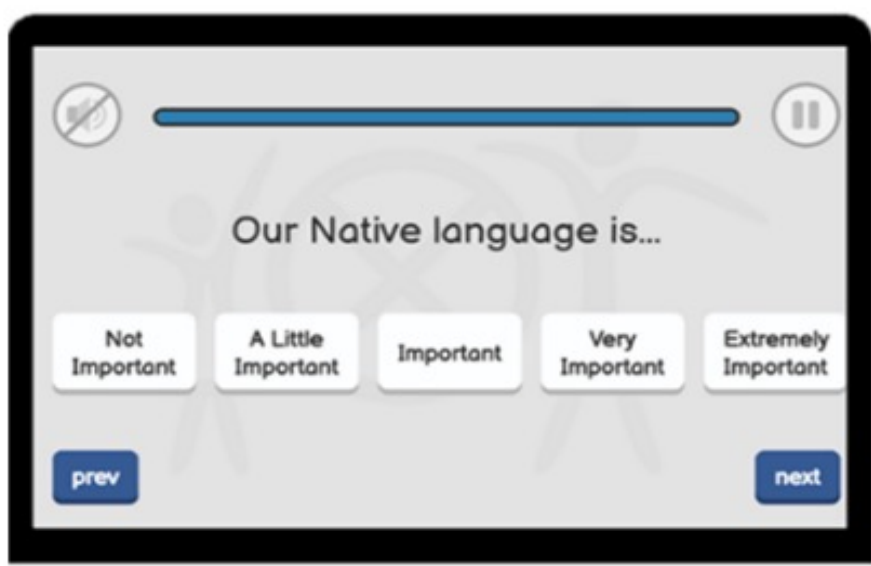

Aaniish Naa Gegii: the Children's Health and Well-being Measure (ACHWM)

The ACHWM provides Indigenous

communities and organizations with an overview of the health and well-being status of the children and youth in their

communities. Developed by Laurentian University and the Naandwechige-Gamig Health Centre in Wiikwemkoong Unceded Territory, partners of the Cundill Centre. 


\section{Cundill Centre Tools:}

Screening, Assessment \& Measurement

\section{Available for free in 3 ways:}

$\rightarrow$ cundillcentre.ca $>$ Innovations in Clinical Care

$\rightarrow$ or e-mail Cundill.Centre@camh.ca

$\rightarrow$ or SCAN the QR code

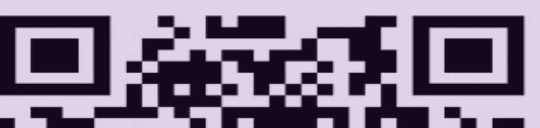

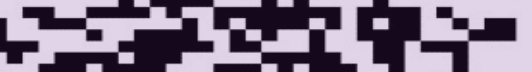
( (5)

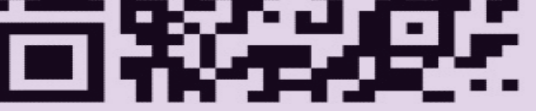

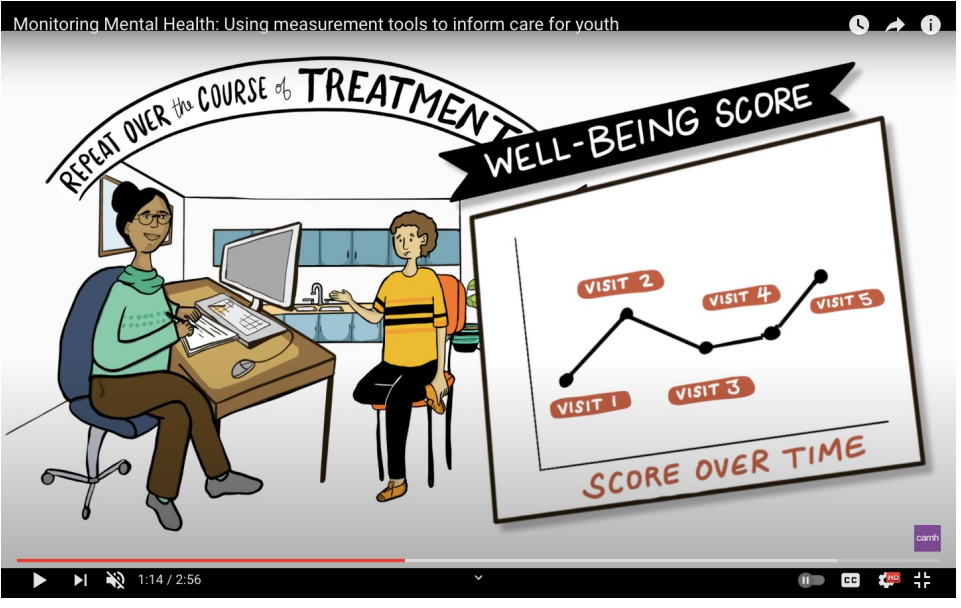

Monitoring Mental Health: Using measurement tools to inform care for youth

In this video (2:56), learn how structured measurement tools can be used to monitor symptom change and help care providers make informed treatment changes (a concept called measurement-based care).

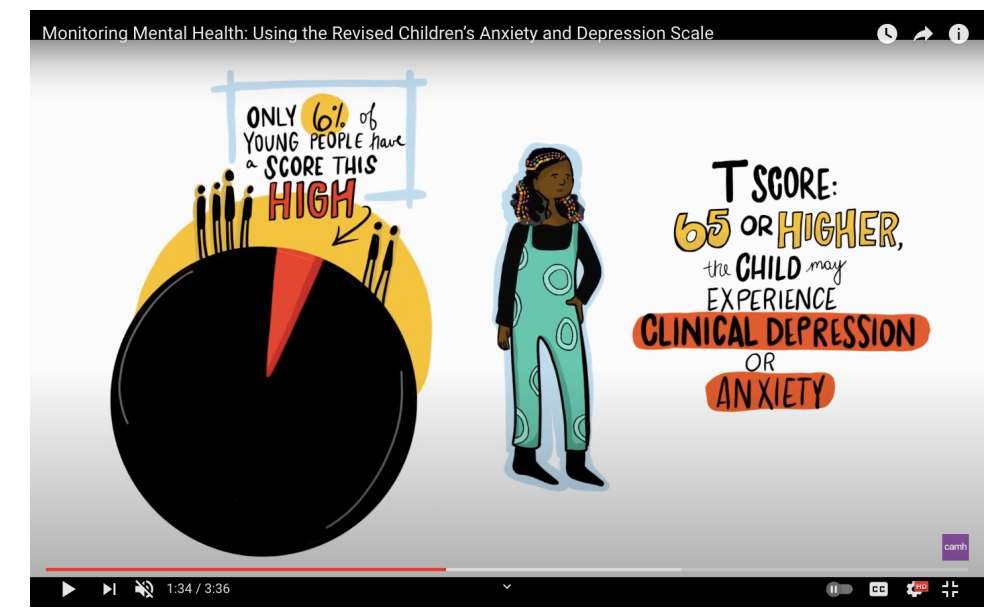

Monitoring Mental Health: Using the Revised Children's Anxiety and Depression Scale (RCADS)

In this video (3:36), learn how to use the RCADS - a free, validated tool that assesses for both anxiety and depression in 8-18 yearolds and is recommended by an international group of experts.

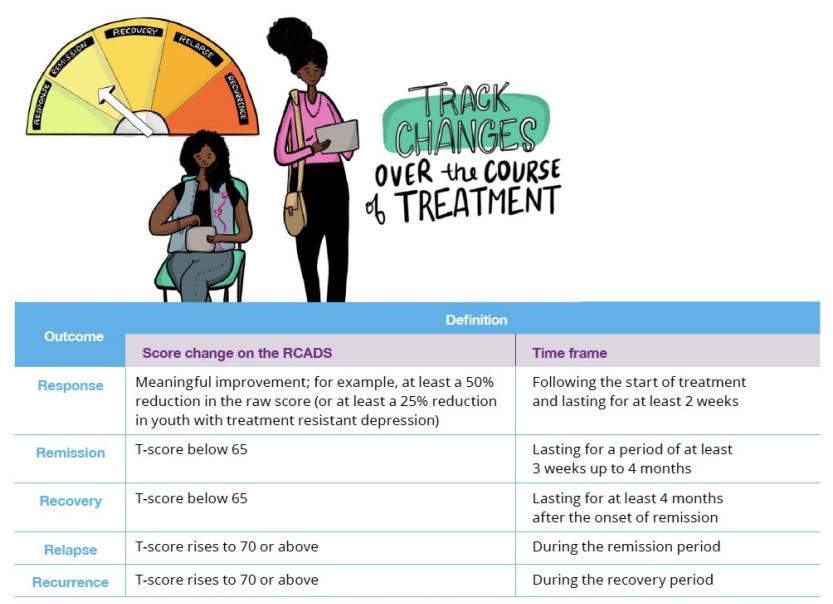

Quick Guide to the Revised Children's Anxiety and Depression Scale (RCADS) Learn more about the RCADS in this Quick Guide, which outlines how the questionnaire is administered and scored. The guide also proposes a way of using RCADS scores to calculate indicators of change, such as response, remission, and recovery. 


\section{Cundill Centre Tools: Psychoeducation}

\section{Available for free in 3 ways:}

$\rightarrow$ cundillcentre.ca > Innovations in Clinical Care

$\rightarrow$ or e-mail Cundill.Centre@camh.ca

$\rightarrow$ or SCAN the QR code

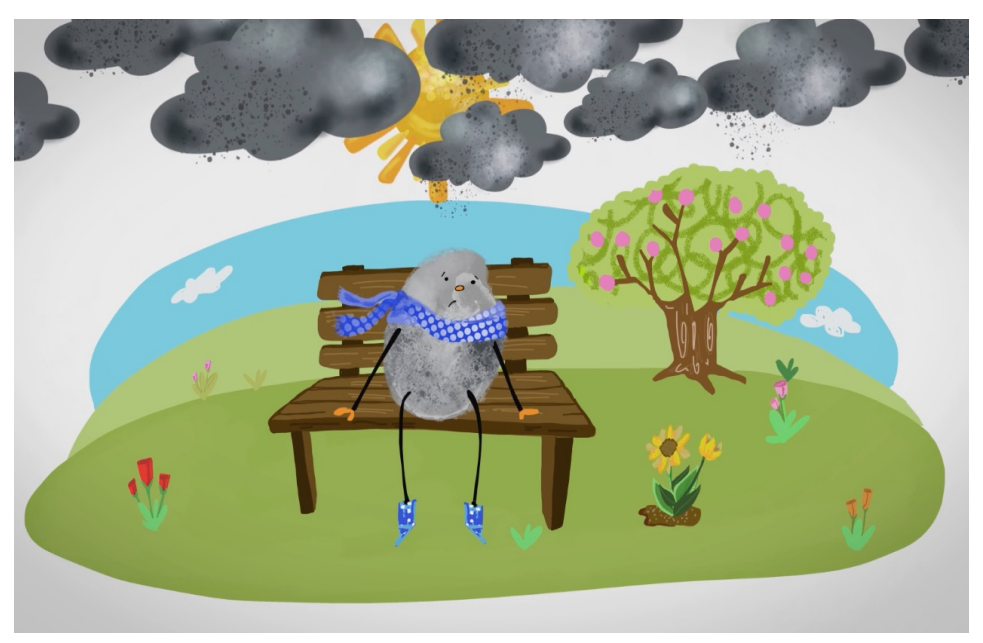

Mood Matters: Describing Depression

Meant for young people, this video (3:19)

describes what depression is, what the causes

might be, what challenges might come up,

and what youth can do to support themselves

or others. Created by youth in collaboration

with mental health professionals.
MOOD FOUNDATIONS

Healthy eating

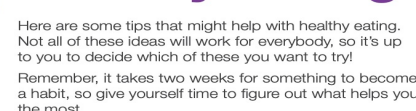

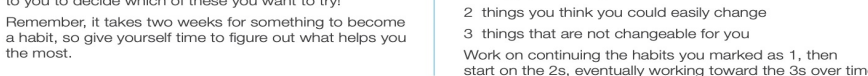

(3)

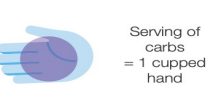

(161)

MEDITERAANEAN DIET

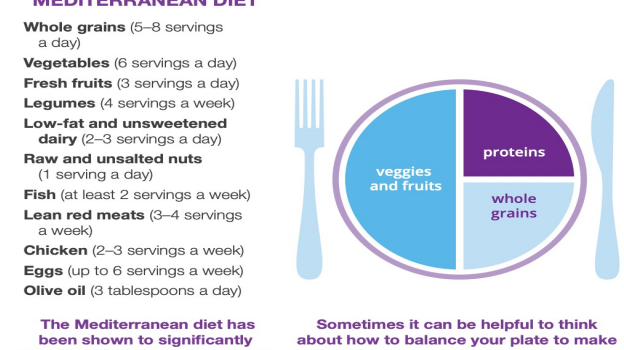

Eᄐ

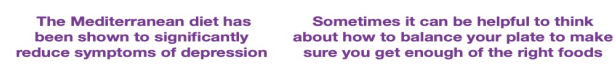

Mood Foundations Package for Youth

Four-page package, including a fact sheet on depression and tips on sleep, exercise and healthy eating. Co-developed by youth, for youth.

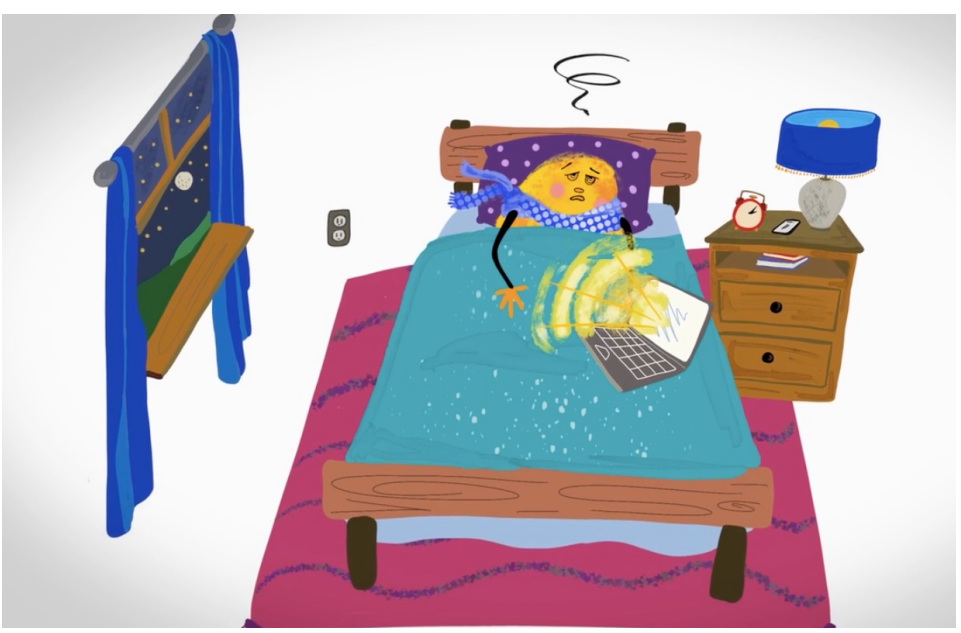

Mood Matters: How Food, Movement \& Sleep Can Have an Impact on You

Meant for young people, this video (4:20) provides tips on healthy eating, movement and sleep habits. Created by youth in collaboration with mental health professionals. 


\section{Cundill Centre Tools: Treatment}

$\rightarrow$ cundillcentre.ca $>$ Innovations in Clinical Care

$\rightarrow$ or e-mail Cundill.Centre@camh.ca

$\rightarrow$ or SCAN the QR code

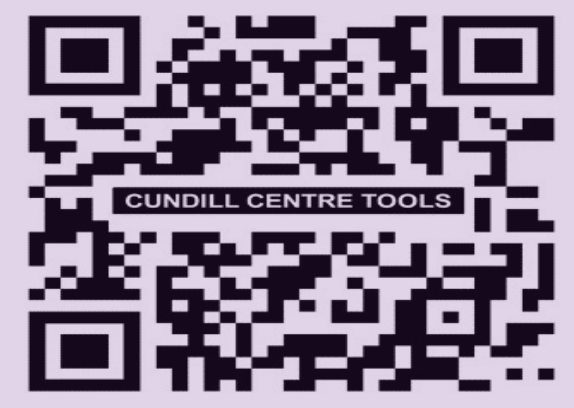

Medication and YOUth

A RESOURCE FOR YOUTH BY YOUTH

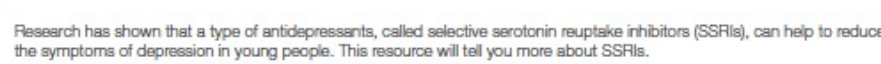
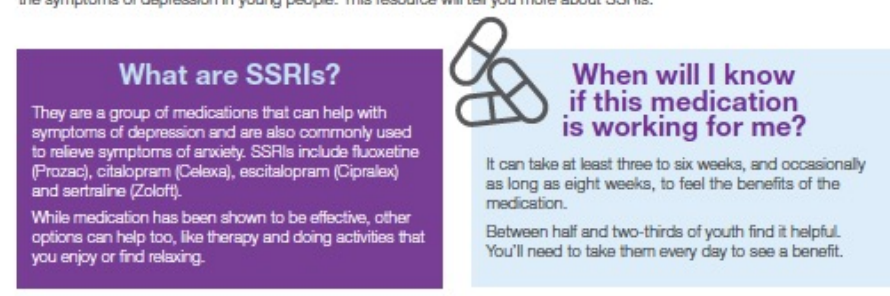

What are some of the side-effects?

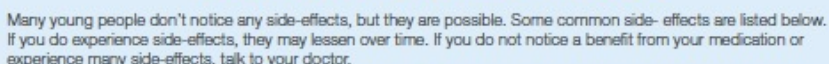

\section{Medication Handout for Youth}

Explains, in simple language, what SSRIs are, when youth might see benefits and what side effects, if any, can occur. Developed by youth in partnership with a psychiatrist and pharmacist.
The Downward Spiral

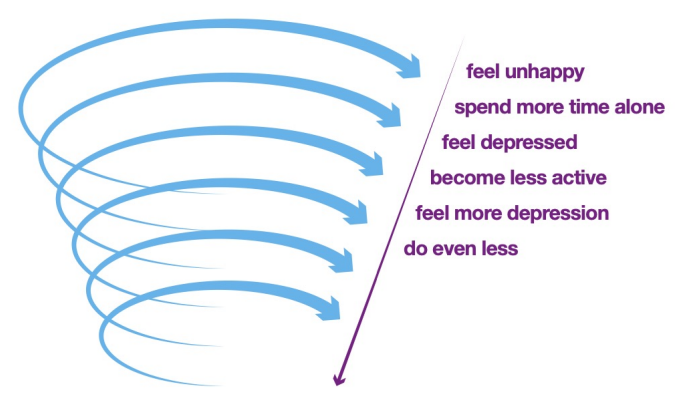

Do you recognize this downward spiral in yourself?

Ask if participants have noticed a downward spiral in themselves and ask them to give examples. Also elicit

\section{CARIBOU CBT Manual}

Facilitator and youth manuals for a cognitive behavioural therapy intervention for adolescents with depression. Modified from with Adolescent Coping with Depression Course, with permission, and updated for today's youth.
Changing Your Thoughts

OPTIONS FOR WHAT TO DO NEXT

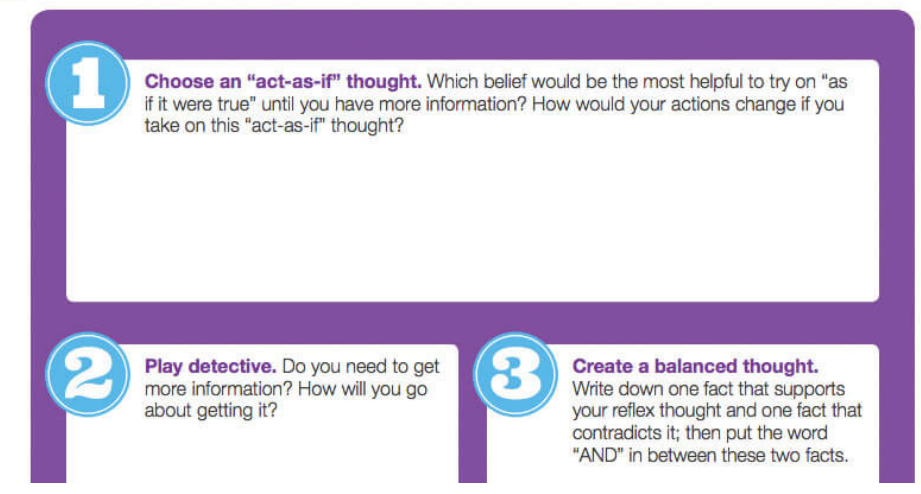

Cognitive Restructuring Worksheets

This three-page package helps youth examine thoughts that may not be helpful to them. It teaches youth how to change their thoughts by considering alternative ways of interpreting situations. Developed by youth and mental health professionals. 


\section{Cundill Centre Tools: Treatment-Problem Solving}

\section{Available for free in 3 ways:}

$\rightarrow$ cundillcentre.ca $>$ Innovations in Clinical Care $\rightarrow$ or e-mail Cundill.Centre@camh.ca $\rightarrow$ or SCAN the QR code gas: S

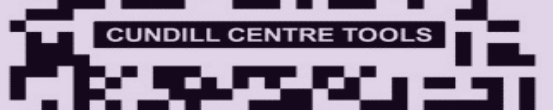
(5:3

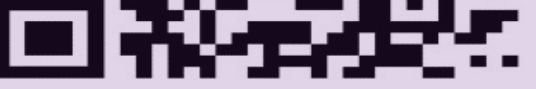

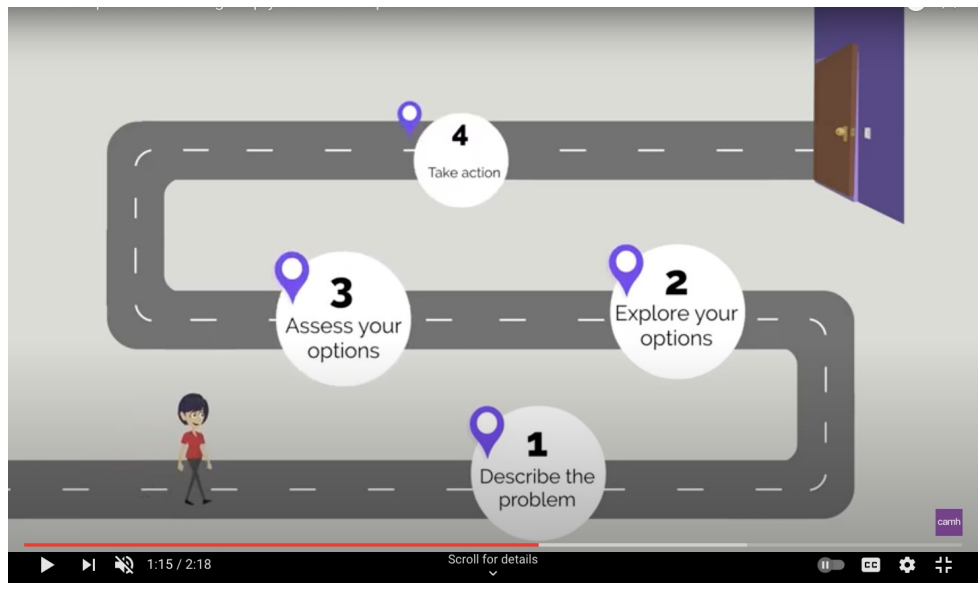

How can problem solving help youth with depression?

Meant for young people, this video (2:18) describes how problem solving can be one important ingredient in tacking depression. Developed by youth and mental health professionals, with funding from the Wellcome Trust.
Is problem-solving training a key ingredient in reducing youth depression?
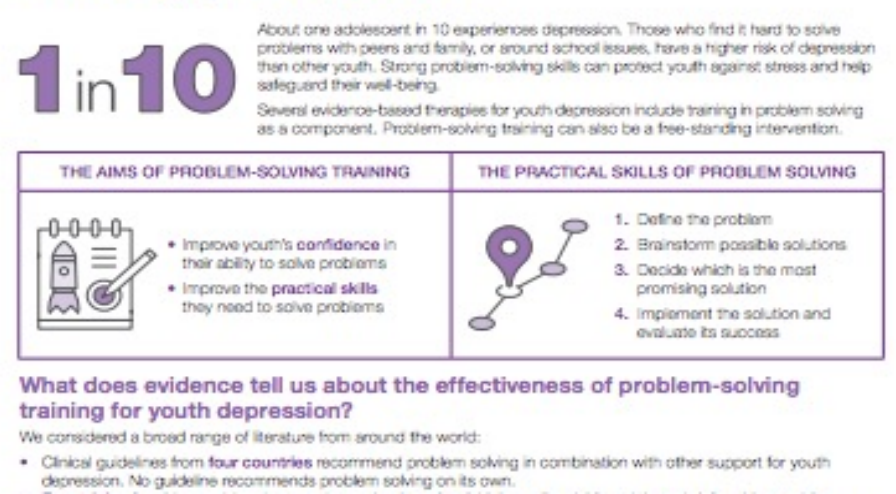

Is problem-solving training a key ingredient in reducing youth depression?

Meant for health care providers and policy decision-makers, this info sheet gives an overview of problem-solving training and summarizes key findings and implications based on a review of the evidence for problem-solving as an effective treatment ingredient for youth depression.

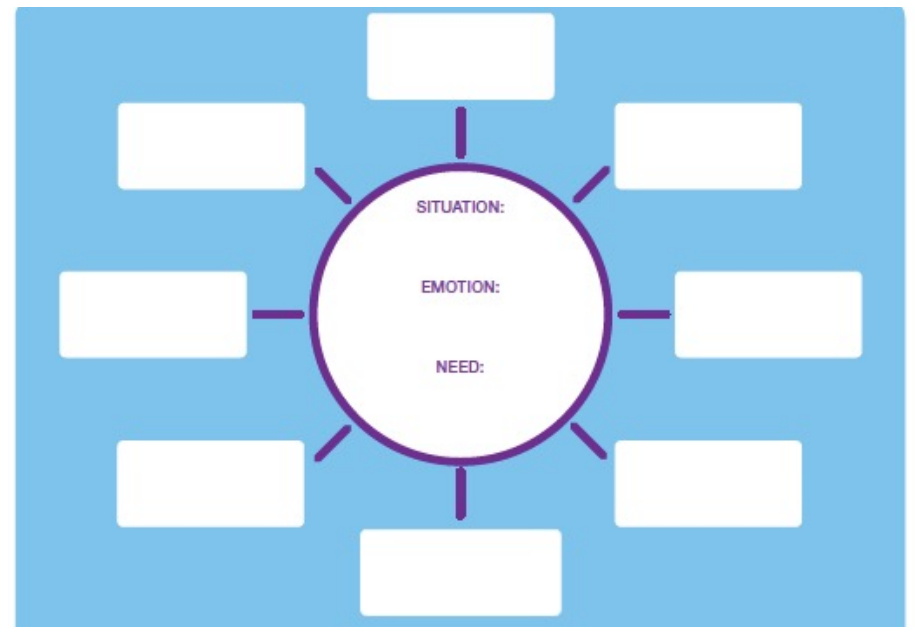

Problem Solving Worksheets

This three-page package helps youth think through their problems by prompting them to describe the situation, as well as their emotions and needs. It takes youth through steps that help them explore and evaluate solutions and make an action plan. Developed by youth and mental health professionals. 


\section{THANK YOU!}

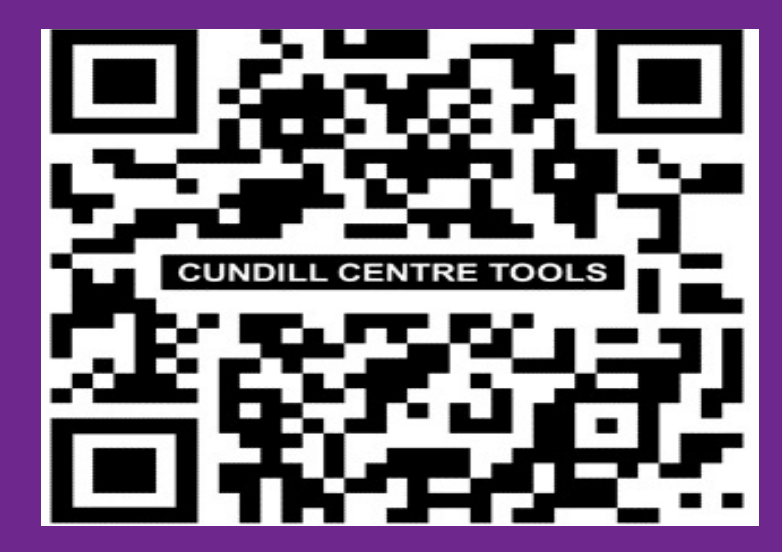

Direct link to online tool:

$\rightarrow$ cundilldepressioncaretool.camh.ca

Link to all Cundill Centre tools:

$\rightarrow$ cundillcentre.ca > Innovations in Clinical Care

Ask questions, leave comments, sign up to hear about the latest tools \& events:

$\rightarrow$ Cundill.Centre@camh.ca 